OPEN ACCESS

Edited by:

Xiao-Yong Fan,

Fudan University, China

Reviewed by:

Alasdair Leslie,

Africa Health Research Institute

(AHRI), South Africa

Pooja Vir,

Uniformed Services University of the

Health Sciences, United States

*Correspondence:

Xueqiong Wu

xueqiongwu@139.com

Specialty section:

This article was submitted to Infectious Agents and Disease,

a section of the journal

Frontiers in Microbiology

Received: 22 July 2021

Accepted: 24 September 2021

Published: 22 October 2021

Citation:

Gong W and Wu X (2021)

Differential Diagnosis of Latent Tuberculosis Infection and Active Tuberculosis: A Key to a Successful

Tuberculosis Control Strategy.

Front. Microbiol. 12:745592.

doi: 10.3389/fmicb.2021.745592

\section{Differential Diagnosis of Latent Tuberculosis Infection and Active Tuberculosis: A Key to a Successful Tuberculosis Control Strategy}

\author{
Wenping Gong and Xueqiong $W u^{*}$ \\ Tuberculosis Prevention and Control Key Laboratory/Beijing Key Laboratory of New Techniques of Tuberculosis Diagnosis \\ and Treatment, Senior Department of Tuberculosis, The 8th Medical Center of PLA General Hospital, Beijing, China
}

As an ancient infectious disease, tuberculosis (TB) is still the leading cause of death from a single infectious agent worldwide. Latent TB infection (LTBI) has been recognized as the largest source of new TB cases and is one of the biggest obstacles to achieving the aim of the End TB Strategy. The latest data indicate that a considerable percentage of the population with LTBI and the lack of differential diagnosis between LTBI and active TB (aTB) may be potential reasons for the high TB morbidity and mortality in countries with high TB burdens. The tuberculin skin test (TST) has been used to diagnose TB for $>100$ years, but it fails to distinguish patients with LTBI from those with aTB and people who have received Bacillus Calmette-Guérin vaccination. To overcome the limitations of TST, several new skin tests and interferon-gamma release assays have been developed, such as the Diaskintest, C-Tb skin test, EC-Test, and T-cell spot of the TB assay, QuantiFERON-TB Gold In-Tube, QuantiFERON-TB Gold-Plus, LIAISON QuantiFERONTB Gold Plus test, and LIOFeron TB/LTBI. However, these methods cannot distinguish LTBI from aTB. To investigate the reasons why all these methods cannot distinguish LTBI from aTB, we have explained the concept and definition of LTBI and expounded on the immunological mechanism of LTBI in this review. In addition, we have outlined the research status, future directions, and challenges of LTBI differential diagnosis, including novel biomarkers derived from Mycobacterium tuberculosis and hosts, new models and algorithms, omics technologies, and microbiota.

Keywords: tuberculosis, latent TB infection (LTBI), tuberculin skin test (TST), interferon-gamma release assays (IGRAs), biomarkers, differential diagnosis

\footnotetext{
Abbreviations: Ala-DH, alanine dehydrogenase; ARI, annual risk in infection; aTB, active tuberculosis; AUCs, areas under the curve; BCG, Bacillus Calmette-Guérin; CFP-10, culture filtrate protein 10; CLIA, chemiluminescent immunoassay; CTL, cytotoxic T lymphocytes; DCs, dendritic cells; DC-SIGN, DC-specific intercellular adhesion molecule3 grabbing nonintegrin; DosRs, dormancy survival regulon antigens; EGF, epidermal growth factor; ELISA, enzymelinked immunosorbent assay; ELISpot, enzyme-linked immunospot; ESAT-6, early secreted antigenic target 6; GM-CSF granulocyte macrophage colony-stimulating factor; HCs, health controls; HCWs, healthcare workers; HLAs, human leukocyte antigens; IFN- $\gamma$, interferon- $\gamma$; IGRAs, interferon-gamma release assays; IL, interleukin; IP-10, interferon-gammainducible protein 10; IS, ImmunoScore; LTBI, latent tuberculosis infection; MIP-1 $\beta$, macrophage inflammatory protein $1 \beta$; NS, nutrition starvation; NTM, non-tuberculous mycobacteria; OT, old tuberculin; PPD, purified protein derivative; PPRs, pattern recognition receptors; QFT-GIT, QuantiFERON-TB Gold In-Tube; QFT-Plus, QuantiFERON-TB Gold-Plus; RAs, reactivation antigens; RD, region of difference; RPF, resuscitation-promoting factor; TAS, toxin-antitoxin systemassociated antigens; TB, tuberculosis; Th, helper T lymphocytes; TLR, toll-like receptor; TNF- $\alpha$, tumor necrosis factor- $\alpha$ Tregs, regulatory T cells; T-SPOT.TB, T-cell spot of TB assay; TST, tuberculin skin test; VEGF, vascular endothelial growth factor; WHO, World Health Organization.
} 


\section{INTRODUCTION}

Tuberculosis (TB) is one of the top 10 causes of death and is the leading cause of death from a single infectious agent worldwide (Gong et al., 2018; WHO, 2020). According to the Global Tuberculosis Report 2020 released by the World Health Organization (WHO), more than 10 million new TB cases and 1.4 million deaths were reported to the WHO in 2019 (WHO, 2020).

To reverse the long-term unfavorable situation of $\mathrm{TB}$ prevention and treatment, the WHO formulated an ambitious End TB Strategy in 2015. The aim of this strategy was to reduce the mortality and incidence rates of TB by $90 \%$ and $80 \%$, respectively, in 2025 from those reported in 2015 and aim for further reduction by $95 \%$ and $90 \%$ in 2035 , respectively (Stop TB Partnership, 2015). Currently, the global incidence of TB is declining at an average rate of about $2 \%$ per year, which is not fast enough to reach the target of a $17 \%$ annual decline from 2025 to 2035 set by the End TB Strategy (Stop TB Partnership, 2015; Chaw et al., 2020).

A reason for this gap may be that the source of infection has not been effectively controlled, resulting in a large percentage of the population being infected with latent TB infection (LTBI). A previous study indicated that $23 \%$ of the world's population (equivalent to 1.7 billion people) was estimated to be latently infected with Mycobacterium tuberculosis, and cases from three WHO regions (Southeast Asia, Western-Pacific, and Africa), which had the highest LBTI burdens, accounted for approximately $80 \%$ of all LTBI cases (Houben and Dodd, 2016). Although countries with high TB burdens pay great importance to the prevention, diagnosis, and treatment of active TB (aTB), the same cannot be said in terms of their emphasis on LTBI.

It has been reported that $5-10 \%$ of patients with LTBI will progress to aTB during their lifetime (Hauck et al., 2009; Chee et al., 2018; WHO, 2018). However, the risk is higher in immunocompromised individuals, such as in people living with human immunodeficiency virus (HIV), people with diabetes, people with coronavirus disease, infants, and young children (aged < 5 years) (Chee et al., 2018; Gong and Wu, 2020; WHO, 2020; Aspatwar et al., 2021). In 2019, the number of new TB cases in countries with high TB burdens accounted for $86.9 \%$ of the global number of new TB cases (WHO, 2020). The latest data indicate that China has the heaviest burden of LTBI worldwide, with about 350 million people latently infected with M. tuberculosis (Cui et al., 2020). These data indicate that a significant percentage of the population with LTBI and lack of differential diagnosis of LTBI and aTB may be potential reasons for the high TB morbidity and mortality in countries with a high TB burden. Therefore, countries with high TB burdens should consider increasingly emphasizing LTBI-related research and taking action to accelerate progress toward global milestones and targets for reductions in the burden of TB set for 2025, 2030, and 2035 (Floyd et al., 2018). Accurately identifying and intervening in cases of TB from the population, especially cases of LTBI, are key to reducing morbidity and mortality. Reaching the milestones of the End TB Strategy is also urgent. Eliminating TB is not feasible if there is no isolation of patients with bacterium-positive
TB and as long as a large number of people with LTBI exist (Godoy, 2021).

In this review, we first clarified the concept and definition of LTBI and then explained the immunological mechanism of LTBI. We also reviewed the current technologies and methods for LTBI differential diagnosis, such as the tuberculin skin test (TST) and interferon-gamma release assays (IGRAs), by comparing their advantages and disadvantages. Finally, we have outlined the current research status, future directions, and challenges for LTBI differential diagnosis in the future, including novel biomarkers derived from M. tuberculosis and its host, new models, algorithms, omics technologies, and microbiota.

\section{CONCEPT AND IMMUNOLOGICAL MECHANISMS OF LATENT TUBERCULOSIS INFECTION}

\section{Evolutionary History of the Definition of Latent Tuberculosis Infection}

With developments in science and technology, the understanding of the definition of LTBI has been deepening continuously over a long period. The evolution of the definition of LBTI can be divided into three stages-macropathology, bacteriology, and immunology. In the early 19th century, Louis (1825) and Laennec (1826) found tubercles upon autopsy of asymptomatic patients who had no clinical manifestations of TB before death, and they used the term "latent" TB to describe this condition for the first time. Behr et al. (2021) summarized the definition of LTBI in the 19th century as "Latent TB is a postmortem diagnosis referring to a host with tuberculous pathology in the absence of symptoms." In the 20th century, the definition of LTBI began to shift from a pathological description to bacteriological identification. As early as 1956, when McCune et al. (1956) identified the effect of pyrazinamide on mice, they accidentally found that the disappearance of $M$. tuberculosis in the organs of mice did not mean that M. tuberculosis was completely eliminated. In contrast, M. tuberculosis can still be identified in approximately one-third of mice treated with pyrazinamide for 90 days. The bacteriological concept of LTBI was first proposed as follows: "the infection is present but is hidden beyond the limits of diagnostic reach" or "the presence of tubercle bacilli in the animal tissues can no longer be demonstrated by the most elaborate techniques of microscopy, culture, or animal inoculation" (McCune et al., 1956; Mc, 1959). However, this description is only a clinical and bacteriological definition but does not reflect the nature of LTBI. Behr et al. (2021) summarized the definition of LTBI in the 20th century as "Latent TB remains a postmortem diagnosis but now referring to the tubercle bacilli recovered from autopsy tissue without TB pathology." In the 21st century, the definition of LTBI has changed from postmortem pathological diagnosis in the 19th century and bacterial diagnosis in the 20th century to host immunological diagnosis. In 1999, the American Thoracic Society (ATS) issued guidelines for the treatment of TB and specifically addressed "latent tuberculosis 
infection" (ATS, 2000). For the first time, TB immunoreactivity tests such as the TST were used to diagnose latent tuberculosis infection. Eight years later, these guidelines were updated, and the definition of LTBI was modified to include "a state of persistent immune response to stimulation by $M$. tuberculosis antigens with no evidence of clinically manifest active TB" (Lewinsohn et al., 2017). This definition of LTBI was recognized by the WHO in their Guidelines on the Management of Latent Tuberculosis Infection (WHO, 2015). On July 15, 2021, Behr et al. (2021) summarized the evolution of the definition of LTBI in the 21st century as follows: "Latent TB refers to a host who is TB immunoreactive in the absence of TB disease."

As mentioned above, the understanding of LTBI has gone through three stages: anatomical diagnosis in the 19th century, bacteriological diagnosis in the 20th century, and immunological diagnosis in the 21st century. However, currently, there is no distinction between a "latent infection" and "immunological memory" in the absence of TB infection. A previous study has found that most TB-immunoreactive individuals retain immunological memory after clearing $M$. tuberculosis infection, indicating $\mathrm{TB}$ immunoreactivity can persist after curative treatment (Behr et al., 2018, 2019). It was estimated that $24.4 \%$ of individuals with $M$. tuberculosis infection could self-clear mycobacteria within 10 years and $73.1 \%$ over a lifetime (Emery et al., 2021). Therefore, the number of people harboring live M. tuberculosis may be substantially lower than previously reported (Behr et al., 2021). The population with positive results of TST and IGRAs includes not only individuals with LTBI but also individuals with persistent $\mathrm{TB}$ immunoreactivity after curative treatment. Furthermore, individuals with LTBI are at risk of progression to active TB. Therefore, they are a potential source of future transmission and may benefit from treatment. In contrast, individuals with immunological memory but no M. tuberculosis infection are not at risk of progression to active TB. Therefore, they are not a source of future transmission from the initial exposure and would not benefit from treatment. Thus, these concerns should be overcome in the future.

In this review, we adopt the definition of LTBI from an article published by Chee et al. (2018) in 2018: "LTBI is a subclinical condition of $M$. tuberculosis infection, characterized by a complex and heterogeneous state resulting from the interaction between the immune response of the organism and the host." In other words, we believe that LTBI is governed by a process of dynamic balance between host immunity and the invasiveness of $M$. tuberculosis. Once the balance is disrupted, M. tuberculosis infection can result in three outcomes (Figure 1A).

\section{Immunological Mechanisms of Latent Tuberculosis Infection}

Host bactericidal immune responses play a central role in the progression from LTBI to aTB (Pan et al., 2017). To better understand the relationship between host immune responses and mycobacteria, we briefly reviewed the immunological mechanisms of LTBI (Figure 1B). As a paradigmatic intracellular pathogen, M. tuberculosis first invades the alveolar epithelial cells (pneumocytes I and II) after host inhalation of droplets containing bacteria via airborne transmission (Chai et al., 2020). The role of alveolar epithelial cells has been well documented in numerous studies since the 1990s (Kanai et al., 1979; Rodrigues et al., 2020). These cells play a crucial role in the pathogenesis of $\mathrm{TB}$ as replicative niches in the spread of infection via cellular death due to $\mathrm{TB}$ infection and play immunomodulatory roles through the expression of cytokines and chemokines (Scordo et al., 2016; Rodrigues et al., 2020). Macrophages are one of the first responders in host defense against $M$. tuberculosis. Inhaled M. tuberculosis is recognized and phagocytosed into phagosomes for clearance by resident alveolar macrophages mainly through their wellequipped pattern recognition receptors (PRRs), which can be blocked by some reactive proteins of $M$. tuberculosis (Westphalen et al., 2014). In addition, in response to $M$. tuberculosis infection, alveolar macrophages secrete a series of pro-inflammatory cytokines and chemokines, such as tumor necrosis factor- $\alpha$ (TNF- $\alpha$ ), interleukin-1 $\beta$ (IL-1 $\beta$ ), IL-6, IL-23, and granulocyte macrophage colony-stimulating factor (GM-CSF) (Chai et al., 2020). Lung-resident dendritic cells (DCs) are another group of sentinel cells that migrate to the surface of the trachea and alveoli to detect invading pathogens in time. Monocyte-derived DCs can recognize $M$. tuberculosis in collaboration with DCspecific intercellular adhesion molecule-3 grabbing non-integrin (DC-SIGN) and toll-like receptor (TLR) and kill M. tuberculosis by upregulating IL-1 $\alpha$, IL-1 $\beta$, IL-10, and inducible nitric oxide synthase (iNOS) (Tailleux et al., 2003; Mayer-Barber et al., 2011; Chai et al., 2020). After phagocytosis of M. tuberculosis, DCs migrate to the surrounding lymph nodes and present the antigens of $M$. tuberculosis to prime $\mathrm{CD} 4^{+} \mathrm{T}$ lymphocytes (Chai et al., 2020).

Unlike macrophages and DCs, neutrophils do not recognize and phagocytose mycobacteria at the original infection sites. Neutrophils are important responders in host defense against $M$. tuberculosis, but they have been neglected until recently. Neutrophil recruitment occurs at an early stage of granuloma formation. In granulomas, the dying macrophages infected with $M$. tuberculosis release signals to recruit neutrophils to phagocytose them and M. tuberculosis (Yang et al., 2012). Previous studies revealed that neutrophils contribute to immune resistance to $\mathrm{TB}$ by producing antimicrobial peptides, facilitating the migration of DCs, and exerting protective effects on the oxidative killing of mycobacteria in TB granulomas (Martineau et al., 2007; Yang et al., 2012). Furthermore, accumulating evidence shows that B cells, natural killer (NK) cells, and mucosal-associated invariant $\mathrm{T}$ (MAIT) cells also play an important role in the immune response against $M$. tuberculosis by interacting with various immune cells, such as macrophages, T cells, and neutrophils (Achkar et al., 2015; Allen et al., 2015; Gong et al., 2021; Sakai et al., 2021).

However, the adaptive immune response is not triggered immediately; it has an interval of 2-3 weeks, which may be conducive to M. tuberculosis colonization (Jasenosky et al., 2015). Subsequently, $\mathrm{T}$ lymphocytes are activated and differentiate into interferon- $\gamma$-positive $\left(\mathrm{IFN}-\gamma^{+}\right)$Th1 cells $\left(\mathrm{CD} 4^{+} \mathrm{T}\right.$ cells), cytotoxic $\mathrm{T}$ lymphocytes (CD8 ${ }^{+} \mathrm{T}$ cells), Th17 cells, Th2 cells, and regulatory $\mathrm{T}$ cells (Tregs) (Chai et al., 2020). These activated 

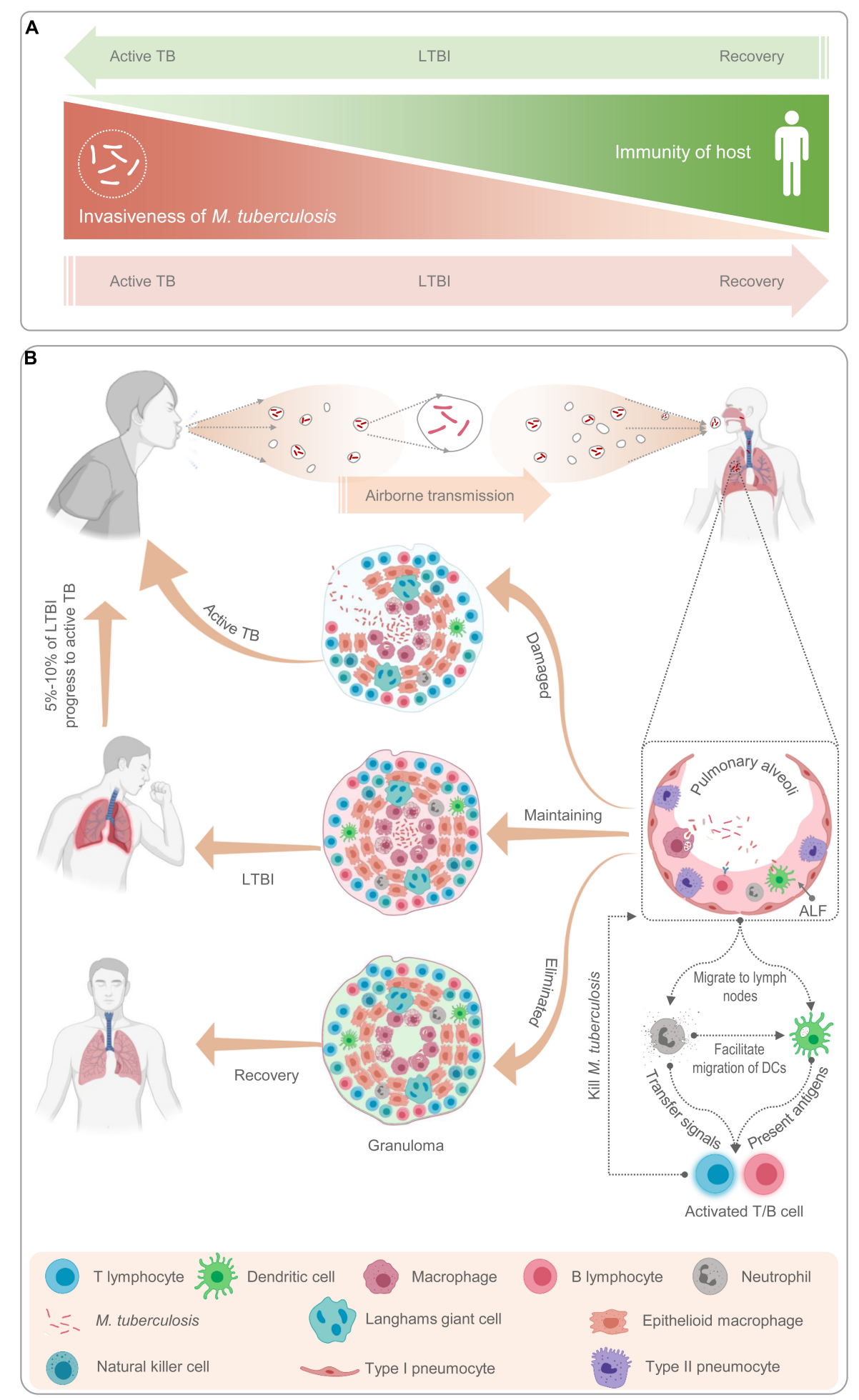

FIGURE 1 | Schematic diagram of latent tuberculosis infection and its mechanism. Latent tuberculosis infection (LTBI) is a balance between immunity of host and invasiveness of $M$. tuberculosis; any tilt would upset the balance (A). The M. tuberculosis excreted from patients with active TB is inhaled by healthy people through airborne transmission and recognized and phagocytized by antigen-presenting cells such as macrophages, neutrophils, natural killer cells, and B lymphocytes (B). Then, neutrophils release cytokines to activate and recruit T lymphocytes to gather at the place where $M$. tuberculosis invades to form granulomas (B). If the host immunity is strong, $M$. tuberculosis will be cleared by immune cells and the host recovers; If the host immunity is weak, $M$. tuberculosis will reproduce in the granulomatous tissue and breaks through the granulomatous restriction to cause active TB; If the immunity of host and invasiveness of $M$. tuberculosis is balanced, the host will be latently infected $(\mathbf{A}, \mathbf{B})$. 
effector cells enter the blood circulation, migrate to the site of M. tuberculosis infection, and participate in local anti-TB immunity. At this stage, granulomas begin to form, and TST and IGRA results may be positive. The formation of tuberculous granulomas is a dynamic process between growth and decline. TB granulomas are the main battlefields for host immune cells and $M$. tuberculosis. The dying immune cells expose the hidden M. tuberculosis to the external environment to be phagocytosed and killed by the new immune cells. This process changes with the strength of the two belligerents, and the result directly affects the outcome of TB infection (Marino et al., 2015).

\section{CURRENT METHODS USED TO DIAGNOSIS LATENT TUBERCULOSIS INFECTION}

It has been reported that approximately one-fourth of the global population is latently infected with $M$. tuberculosis and that $5-15 \%$ of them may progress to aTB within 2 years, while the remaining individuals with LTBI are at a constant risk of reactivation (Houben and Dodd, 2016; Pai and Behr, 2016). The differential diagnosis of individuals with LTBI can not only promote an understanding of the pathogenesis of TB but also reduce the risk of progression of LTBI to aTB through preventive treatment. However, there is no specific gold standard test for diagnosing LTBI thus far (Chee et al., 2018). Currently, the diagnosis of LTBI mainly depends on the host's positive immune response to the antigens of $M$. tuberculosis and the clinical manifestations of the host. Currently, two methods are endorsed by the WHO as tests for TB infection-the century-old TST and IGRAs, which have been introduced since 2005 (Zellweger et al., 2020). The characteristics of the TST and IGRAs are listed in Table 1.

\section{Skin Tests}

\section{Conventional Tuberculin Skin Test}

The TST is a diagnostic method performed through subcutaneous injection of old tuberculin (OT) or purified protein derivative (PPD) as an antigen (Mosavari et al., 2021). It has been applied in the screening, diagnosis, and epidemiological studies of primary infection with $M$. tuberculosis for more than 100 years and is the main diagnostic test for LTBI. The TST is widely used to screen and detect $\mathrm{TB}$ owing to its advantages of being affordable, being simple to perform, and the requirement of minimal laboratory equipment. However, its disadvantages cannot be neglected, such as its requirement for a second visit after 48-72 h, inability to distinguish LTBI from aTB, false positives with Bacillus Calmette-Guérin (BCG) vaccination, cross-reactivity with non-tuberculous mycobacteria (NTM), and false negatives in immunosuppression and deficiency (Pourakbari et al., 2019).

\section{Novel Emerging Skin Tests}

In addition to the conventional TST, three novel strategies for the diagnosis of TB have been developed in recent years-Diaskintest (Generium Pharmaceutical, Moscow, Russia), C-Tb skin test
(Statens Serum Institut, Copenhagen, Denmark), and EC-Test (Zhifei Longcom Biologic Pharmacy Co., Anhui, China) (Steffen et al., 2020; WHO, 2020). The Diaskintest is a new effective way to identify the initial presentation of TB and developed based on a fusion protein of the early secreted antigenic target 6 (ESAT-6) and culture filtrate protein 10 (CFP-10) antigens present in virulent strains of $M$. tuberculosis, which are absent in the BCG strain and in most NTMs. Recently, a meta-analysis based on 61 articles and 3,777,083 patients was conducted to evaluate the sensitivity and accuracy of the Diaskintest, and the results indicated that the overall diagnostic specificity, sensitivity, and accuracy of the Diaskintest were 98.0, 86.0, and 95.1\%, respectively (Starshinova et al., 2020). However, the C-terminal of the fusion protein used in the Diaskintest contains 11 amino acids (including six histidine (HIS) labels) on the vector sequence other than the target gene, which does not conform to the "Technical Guiding Principles for Quality Control of Recombined DNA Products for Human Use" issued by the China Food and Drug Administration. The novel $\mathrm{C}$-Tb skin test is based on a mixture of antigens ESAT-6 and CFP10. It combines the advantages of the field friendliness of TST and the high specificity of IGRAs. Two phase III clinical trials have investigated the safety and efficacy of the C-Tb skin test, QuantiFERON-TB Gold In-Tube (QFT-GIT), and TST, suggesting that C-Tb and QFT-GIT results were concordant in $94 \%$ of participants and that the safety profile of the $\mathrm{C}-\mathrm{Tb}$ skin test was similar to that of the TST and QFT-GIT in HIV-negative adults and children as well as HIV-positive individuals with active or latent M. tuberculosis infection (Ruhwald et al., 2017; Aggerbeck et al., 2018). The EC-Test is the latest skin test for the diagnosis of aTB and LTBI. Similar to the Diaskintest and C-Tb skin test, the ECTest is also developed based on ESAT- 6 and CFP10 antigens of M. tuberculosis. Currently, clinical phase I, II, and III trials of the EC-Test have been completed. A phase I clinical trial and a phase IIa clinical trial indicated that the median maximum induration diameter of the EC-Test was similar to that of the TST and that a single dose of the EC-Test $(1,5,10$, or $20 \mu \mathrm{g} / \mathrm{ml})$ was well tolerated and safe, with its diagnostic accuracy superior to that of the TST (Li et al., 2016a,b). A phase III clinical trial conducted in 1,559 participants found that the EC-Test and IGRAs have fairly high specificity and consistency (88.77\%) (Chinese Antituberculosis Association et al., 2020).

Taken together, these three new tests are designed to detect immune responses stimulated with recombinant ESAT- 6 and CFP-10 antigens to help address the problem of false-positive TST results that occur in patients who have received BCG vaccination (Ruhwald et al., 2016). Their specificity may be higher than that of the TST and may be more accurate, acceptable, and cheaper alternatives to IGRAs (Ruhwald et al., 2017). These skin tests have the advantages of the TST and IGRAs, which are characterized by simple operation, low cost, and easy reading of results, making it possible to apply them in countries with a high burden of TB and in poverty-stricken areas, especially in countries implementing universal BCG vaccination. Furthermore, increasingly emerging studies have demonstrated that these new skin tests show similar test positivity rates, safety profiles, and specificities to those of IGRAs and provide 
TABLE 1 | The characteristics of the skin tests and IGRAs.

\begin{tabular}{|c|c|c|c|c|c|c|c|c|c|}
\hline \multirow[t]{2}{*}{ Terms } & \multicolumn{4}{|c|}{ Skin tests } & \multicolumn{5}{|c|}{ IGRAs } \\
\hline & Conventional TST & Diaskintest & C-Tb skin test & EC-Test & T-SPOT.TB & QFT-GIT & QFT-Plus & LIAISON QFT-Plus & LIOFeron TB/LTBI \\
\hline Manufacturer & Multiple manufacturers & $\begin{array}{l}\text { Generium } \\
\text { Pharmaceutical, Russia }\end{array}$ & $\begin{array}{l}\text { Statens Serum Institut, } \\
\text { Denmark }\end{array}$ & Zhifei Longcom, China & $\begin{array}{l}\text { Oxford Immunotec, } \\
\text { United Kingdom }\end{array}$ & $\begin{array}{l}\text { QIAGEN, Hilden, } \\
\text { Germany }\end{array}$ & $\begin{array}{l}\text { Qiagen, MD, } \\
\text { United States }\end{array}$ & DiaSorin S.p.A., Italy & $\begin{array}{l}\text { LIONEX GmbH, } \\
\text { Braunschweig, } \\
\text { Germany }\end{array}$ \\
\hline Time & $>100$ years & 2009 & 2010 & 2020 & 1990s & 1980s & 2015 & 2017 & 2019 \\
\hline Antigens & PPD & ESAT- 6 and CFP10 & ESAT- 6 and CFP 10 & ESAT-6 and CFP10 & ESAT-6 and CFP10 & $\begin{array}{l}\text { ESAT-6, CFP-10, and } \\
\text { TB7.7 (p4) }\end{array}$ & ESAT- 6 and CFP10 & ESAT-6 and CFP10 & $\begin{array}{l}\text { ESAT-6, CFP-10, } \\
\text { TB7.7, Ala-DH }\end{array}$ \\
\hline Tubes & NA & NA & NA & NA & One tube & $\begin{array}{l}\text { Nil tube, Antigen tube, } \\
\text { and Mitogen tube }\end{array}$ & $\begin{array}{l}\text { Nil tube, TB1 tube, TB2 } \\
\text { tube, and Mitogen tube }\end{array}$ & $\begin{array}{l}\text { Nil tube, TB1 tube, TB2 } \\
\text { tube, and Mitogen tube }\end{array}$ & $\begin{array}{l}\text { PC tube, TB-A tube, } \\
\text { TB-B tube, and NC } \\
\text { tube }\end{array}$ \\
\hline Technological platform & NA & NA & NA & NA & ELISPOT & ELISA & ELISA & CLIA & ELISA \\
\hline Sample & NA & NA & NA & NA & PBMCs & Whole blood & Whole blood & Whole blood & Whole blood \\
\hline $\begin{array}{l}\text { Sample transport and } \\
\text { storage temperature }\end{array}$ & Refrigerate at $4^{\circ} \mathrm{C}$ & Refrigerate at $4^{\circ} \mathrm{C}$ & Refrigerate at $4^{\circ} \mathrm{C}$ & Refrigerate at $4^{\circ} \mathrm{C}$ & $\begin{array}{l}\text { Indoor temperature, do } \\
\text { not refrigerate or freeze }\end{array}$ & $\begin{array}{l}\text { Indoor temperature, do } \\
\text { not refrigerate or freeze }\end{array}$ & $\begin{array}{l}\text { Indoor temperature, do } \\
\text { not refrigerate or freeze }\end{array}$ & $\begin{array}{l}\text { Indoor temperature, do } \\
\text { not refrigerate or freeze }\end{array}$ & $\begin{array}{l}\text { Indoor temperature, do } \\
\text { not refrigerate or freeze }\end{array}$ \\
\hline Outcome measure & Millimeters of induration & Millimeters of induration & Millimeters of induration & Millimeters of induration & $\begin{array}{l}\text { Number of } \\
\text { IFN- }- \text {-producing T cells }\end{array}$ & $\begin{array}{l}\text { Serum concentration of } \\
\text { IFN- } \gamma \text { produced by } \\
\text { CD4+T cells }\end{array}$ & $\begin{array}{l}\text { Serum concentration of } \\
\text { IFN- } \gamma \text { produced by } \\
\text { CD4+ and CD8+T cells }\end{array}$ & $\begin{array}{l}\text { Serum concentration of } \\
\text { IFN- } \gamma \text { produced by } \\
\text { CD4+ and CD8+T cells }\end{array}$ & $\begin{array}{l}\text { Serum concentration of } \\
\text { IFN- } \gamma \text { produced by } \\
\text { CD4+ and CD8+T cells }\end{array}$ \\
\hline Positive internal control & No & No & No & No & PHA & Mitogen & Mitogen & Mitogen & Unknown \\
\hline Need for return visit & Yes & Yes & Yes & Yes & No & No & No & No & No \\
\hline $\begin{array}{l}\text { Time required for } \\
\text { results }\end{array}$ & $48-72 \mathrm{~h}$ & $48-72 \mathrm{~h}$ & $48-72 \mathrm{~h}$ & $48-72 \mathrm{~h}$ & $16-20 \mathrm{~h}$ & $16-24 \mathrm{~h}$ & $16-24 \mathrm{~h}$ & Unknown & $16-24 \mathrm{~h}$ \\
\hline in vivo/in vitro & in vivo & in vivo & in vivo & in vivo & in vitro & in vitro & in vitro & in vitro & in vitro \\
\hline Interpretation of result & $\begin{array}{l}\text { Subjective } \\
\text { (operator-based) }\end{array}$ & $\begin{array}{l}\text { Subjective } \\
\text { (operator-based) }\end{array}$ & $\begin{array}{l}\text { Subjective } \\
\text { (operator-based) }\end{array}$ & $\begin{array}{l}\text { Subjective } \\
\text { (operator-based) }\end{array}$ & $\begin{array}{l}\text { Objective } \\
\text { (instrument-based) }\end{array}$ & $\begin{array}{l}\text { Objective } \\
\text { (instrument-based) }\end{array}$ & $\begin{array}{l}\text { Objective } \\
\text { (instrument-based) }\end{array}$ & $\begin{array}{l}\text { Objective } \\
\text { (instrument-based) }\end{array}$ & $\begin{array}{l}\text { Objective } \\
\text { (instrument-based) }\end{array}$ \\
\hline $\begin{array}{l}\text { False positives with } \\
\text { BCG vaccination }\end{array}$ & Yes & No & No & No & No & No & No & No & No \\
\hline $\begin{array}{l}\text { Cross-reactivity with } \\
\text { NTMs }\end{array}$ & High & Low & Low & Low & $\begin{array}{l}\text { Low, but can be } \\
\text { influenced by infections } \\
\text { of } M \text {. kansasii, } \\
M . \text { szulgai, } M \text {. marinum, } \\
\text { and } M \text {. gordonae* }\end{array}$ & $\begin{array}{l}\text { Low, but can be } \\
\text { influenced by infections } \\
\text { of } M \text {. kansasii,, } \\
\text { M. szulgai, and } \\
\text { M. marinum (Andersen } \\
\text { et al., 2000) }\end{array}$ & $\begin{array}{l}\text { Low, but can be } \\
\text { influenced by infections } \\
\text { of } M \text {. kansasii, } \\
\text { M. szulgai, and } \\
\text { M. marinum (Andersen } \\
\text { et al., 2000) }\end{array}$ & Unknown & Low \\
\hline $\begin{array}{l}\text { False positives with } \\
\text { immunosuppression } \\
\text { and deficiency }\end{array}$ & High & Low & Low & Low & Low & Low & Low\# & Unknown & Unknown \\
\hline Specificity & $\begin{array}{l}62 \% \text { (BCG vaccinated) } \\
\text { and 95\% (BCG } \\
\text { unvaccinated) (Ruhwald } \\
\text { et al., 2016) }\end{array}$ & $\begin{array}{l}\text { 98\% (Starshinova et al., } \\
\text { 2020) }\end{array}$ & $\begin{array}{l}99.3 \% \text { (Aggerbeck } \\
\text { et al., 2013) }\end{array}$ & $\begin{array}{l}\text { 98\% (Steffen et al., } \\
\text { 2020) }\end{array}$ & $\begin{array}{l}\text { 76.2\% (Yang et al., } \\
\text { 2021) }\end{array}$ & $99 \% \S$ & $\begin{array}{l}\text { 95\% (Sotgiu et al., } \\
\text { 2019) }\end{array}$ & Unknown & $\begin{array}{l}\text { 98\% in aTB and 97\% in } \\
\text { LTBI (Della Bella et al., } \\
\text { 2020) }\end{array}$ \\
\hline Sensitivity & $\begin{array}{l}\text { 75\% (Aggerbeck et al., } \\
2018) \dagger\end{array}$ & $\begin{array}{l}\text { 86\% (Starshinova et al., } \\
\text { 2020) }\end{array}$ & $\begin{array}{l}\text { 73.9\% (Hoff et al., } \\
\text { 2016) }\end{array}$ & $\begin{array}{l}\text { 86\% (Steffen et al., } \\
2020 \text { ) }\end{array}$ & $\begin{array}{l}\text { 83.5\% (Yang et al., } \\
\text { 2021) }\end{array}$ & $\begin{array}{l}89 \% \S \text { §and } 73 \% \\
\text { (Aggerbeck et al., } \\
\text { 2018)† }\end{array}$ & $\begin{array}{l}\text { 91\% (Sotgiu et al., } \\
2019 \text { ) }\end{array}$ & Unknown & $\begin{array}{l}\text { 90\% in aTB and 94\% in } \\
\text { LTBI (Della Bella et al., } \\
\text { 2020) }\end{array}$ \\
\hline Accuracy & Unknown & $\begin{array}{l}95.1 \% \text { in total } \\
\text { population and } 92.4 \% \\
\text { in HIV-positive patients } \\
\text { (Starshinova et al., } \\
\text { 2020) }\end{array}$ & Unknown & $87 \%$ & $\begin{array}{l}\text { 88.5\% (Yang et al., } \\
\text { 2021) }\end{array}$ & Unknown & Unknown & Unknown & Unknown \\
\hline
\end{tabular}




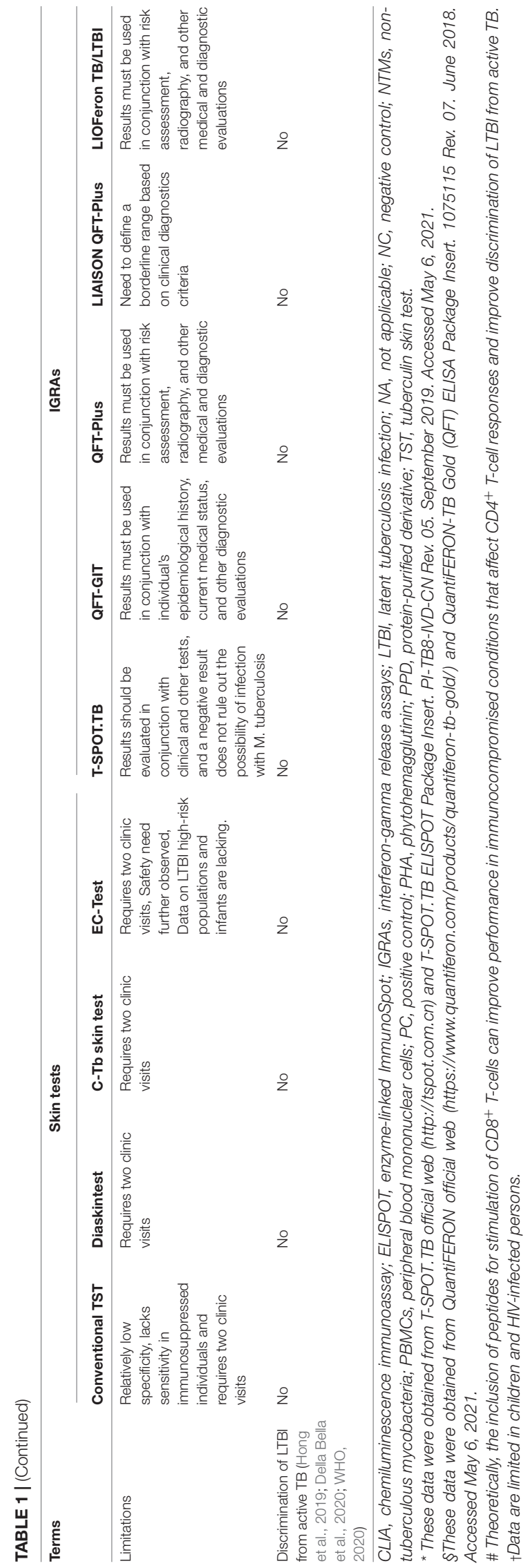

comparable results in terms of diagnosing patients with TB living with HIV and children infected with M. tuberculosis (Table 1; Litvinov et al., 2009; Aggerbeck et al., 2013; Hoff et al., 2016; Ruhwald et al., 2017; Aggerbeck et al., 2018; Steffen et al., 2020).

Nevertheless, the potential drawbacks of these three new skin tests are worth noting. First, these skin tests have insufficient diagnostic foundations for the differential diagnosis of LTBI. Second, vaccines based on recombinant ESAT6-CFP10 protein for prevention of LTBI may affect the diagnostic value of these skin tests in the future. Finally, these three novel skin tests should be validated in larger clinical trials in children, elderly individuals, and special populations such as in HIVinfected persons, immunosuppressant drug users, and people with malnutrition.

\section{Interferon-Gamma Release Assays}

To overcome the deficiencies of the TST, IGRAs have been developed as an alternative immunodiagnostic approach. Thus far, there are five commercialized IGRA kits, including the T-cell spot of the TB assay (T-SPOT.TB, Oxford Immunotec, Abingdon, UK), QuantiFERON-TB Gold In-Tube (QFT-GIT, Qiagen GmbH, Hilden, Germany), QuantiFERON-TB Gold-Plus (QFTPlus, Qiagen, MD, United States), LIAISON QuantiFERON-TB Gold Plus (LIAISON QFT-Plus, DiaSorin S.p.A., Italy), and LIOFeron TB/LTBI (LIONEX GmbH, Braunschweig, Germany) (De Maertelaere et al., 2020; Della Bella et al., 2020; Altawallbeh et al., 2021; Hamada et al., 2021). In addition, there are five products in development-T-Track (R) TB (Lophius Biosciences GmbH), VIDAS TB-IGRA (bioMérieux), Access QuantiFERONTB (Boditech Med Inc.), ichroma ${ }^{\mathrm{TM}}$ IGRATB (Boditech Med Inc.), and IP-10 IGRA elisa/lateral flow (rBioPharm) (WHO, 2020).

\section{T-cell Spot of the Tuberculosis Assay, QuantiFERON- Tuberculosis Gold In-Tube Test, and QuantiFERON- Tuberculosis Gold-Plus}

T-cell spot of the TB assay is an enzyme-linked immunospot (ELISpot) assay developed by Prof. Lalvani in collaboration with his colleagues in the late 1990s (Lalvani et al., 2001). T-SPOT.TB detects the immune responses of peripheral blood-derived IFN$\gamma$-secreting $\mathrm{T}$ cells stimulated with peptides from ESAT-6 and CFP10 antigens. The QFT-GIT assay is based on stimulating IFN- $\gamma$ release from $\mathrm{CD}^{+}{ }^{+} \mathrm{T}$ cells in a single $\mathrm{TB}$ antigen tube with three antigens of $M$. tuberculosis, including ESAT-6, CFP10, and TB7.7. Antigens ESAT-6 and CFP-10 are encoded within the $M$. tuberculosis region of difference 1 (RD1) locus, which eliminates interference from BCG and NTMs (Saracino et al., 2009). The QFT-Plus assay is designed to stimulate CD $4^{+} \mathrm{T}$ cells using ESAT- 6 and CFP-10 antigens in tube 1 (TB1) and elicit IFN$\gamma$ release from both $\mathrm{CD}^{+}$and $\mathrm{CD}^{+} \mathrm{T}$ cells using a cocktail of peptides derived from ESAT- 6 and CFP-10 antigens in TB2 (Rozot et al., 2013). Compared with the QFT-GIT assay based on $\mathrm{CD}^{+}{ }^{+} \mathrm{T}$-cell immune responses, the biggest improvement in the QFT-Plus assay is the addition of $\mathrm{CD}^{+} \mathrm{T}$-cell responses. It has been reported that the $\mathrm{CD}^{+} \mathrm{T}$-cell response in patients with aTB is higher than that in patients with LTBI (Theel et al., 2018). A systematic review and meta-analysis demonstrated 
that QFT-Plus is more sensitive than QFT-GIT for detecting M. tuberculosis infection (Sotgiu et al., 2019), which is consistent with the results of another meta-analysis (Pourakbari et al., 2019). These data suggest that QFT-Plus is more sensitive than QFTGIT in detecting $M$. tuberculosis infection, which may be due to $\mathrm{CD}^{+}$T-cell immune responses in the TB2 tube. Therefore, QFT-Plus was approved by the United States Food and Drug Administration in 2017 to replace QFT-GIT (Theel et al., 2018). In 2019, Venkatappa et al. (2019) evaluated the agreement between QFT-Plus, QFT-GIT, T-SPOT.TB, and the TST in 506 participants at a high risk of LTBI and/or progression to TB disease. Their results showed that there was 94\% agreement between QFT-Plus and QFT-GIT, 77\% agreement between QFTPlus or QFT-GIT and the TST, 92\% agreement between QFTPlus and SPOT.TB, and 91\% agreement between QFT-GIT and T-SPOT.TB. These results indicated a high degree of agreement between QFT-GIT and QFT-Plus in a direct comparison and that all tests were in agreement with the TST and T-SPOT.TB.

\section{LIAISON QuantiFERON- Tuberculosis Gold-Plus}

The LIAISON QFT-Plus test, developed by DiaSorin in collaboration with Qiagen, is a whole blood-based QuantiFERON technology that offers efficient and high-throughput detection with QFT-Plus. The LIAISON QFT-Plus test is a fourthgeneration technology for detecting LTBI. It is an improved version of the QFT-Plus test, in which the enzyme-linked immunosorbent assay (ELISA) in QFT-Plus has been replaced by a chemiluminescent immunoassay (CLIA) (Altawallbeh et al., 2021). A recent study evaluated the diagnostic performance of LIAISON QFT-Plus by comparing it with that of QFTPlus test in 329 participants, showing 92.8, 97.9, and 97.8\% agreement with the QFT-Plus test among patients with aTB, low-risk cohort, and mixed risk cohort participants, respectively (Altawallbeh et al., 2021). Furthermore, LIAISON QFT-Plus test can save time and labor and be a potentially useful addition to streamline LTBI screening (Kadkhoda et al., 2020). Moreover, these findings suggest that the automated LIAISON QFT-Plus test has a diagnostic performance comparable to that of the QFTPlus test and can be applied for LTBI diagnosis. However, given that it is a newly emerging technology, the LIAISON QFT-Plus test requires more studies with large sample sizes to prove its sensitivity and specificity in the future.

\section{LIOFeron Tuberculosis/Latent Tuberculosis Infection Assay}

The LIOFeron TB/LTBI assay, developed by Lionex GmbH (Braunschweig, Germany) in 2019, is a novel IGRA test for diagnosing LTBI and TB (LIONEX, 2021). The LIOFeron TB/LTBI assay contains two components-human blood stimulation tubes (component 01) and human IFN- $\gamma$ ELISA (component 02). Component 01 contains a positive control tube, a negative control tube, and TB antigen tubes. Compared with other IGRAs, the LIOFeron TB/LTBI assay contains not only ESAT-6, CFP-10, and TB7.7 but also a new antigen of M. tuberculosis, alanine dehydrogenase (Ala-DH). Previous studies have reported that Ala-DH is absent in BCG, induces major histocompatibility complex (MHC) class I-restricted $\mathrm{T}$
$\mathrm{CD}^{+}$lymphocytes to produce IFN- $\gamma$, and participates in the adaptation of $M$. tuberculosis to the anaerobic dormant stage in LTBI (Jungblut et al., 1999; Dong et al., 2004; Agren et al., 2008). Recently, the sensitivity and specificity of the novel test were evaluated, and a comparison between its accuracy and that of the QFT-PLUS assay was performed in patients with aTB and LBTI (Della Bella et al., 2020). The results demonstrated that the sensitivity and specificity of the LIOFeron TB/LTBI assay was $90 \%$ and $98 \%$ for diagnosing aTB and $94 \%$ and 97\% for diagnosing LTBI and that the LIOFeron TB/LTBI assay showed higher sensitivity than the QFT-Plus test for LTBI detection (Della Bella et al., 2020). However, like other IGRAs, the LIOFeron TB/LTBI assay cannot differentiate between LTBI and aTB.

\section{RESEARCH STATUS, FUTURE DIRECTIONS, AND CHALLENGES FOR LATENT TUBERCULOSIS INFECTION DIFFERENTIAL DIAGNOSIS}

Current methods such as the Diaskintest, C-Tb skin test, EC-Test, and T-SPOT.TB, QFT-GIT, QFT-Plus, and LIAISON QFT-Plus have greatly improved the accuracy, sensitivity, and specificity of $M$. tuberculosis infection detection, but they are still unable to distinguish LTBI from aTB. Since LTBI is a complicated heterogeneous state reflecting the interaction between $M$. tuberculosis and the host's immune response, the development of a better diagnostic technology that can differentiate LTBI from aTB requires a deep understanding of both the mycobacteria and its host (Chee et al., 2018). Herein, we will start from these two aspects to outline a possible blueprint for the technology exploration of LTBI differential diagnosis in hopes of pointing out directions and laying the foundation for future research on the topic.

\section{Novel Biomarkers Derived From Mycobacterium tuberculosis Antigens}

Mycobacterium tuberculosis proteins encoded by RDs are feasible candidate biomarkers for differentiating M. tuberculosis infection from BCG vaccination (Al-Khodari et al., 2011). As mentioned above, the Diaskintest, C-Tb skin test, EC-Test, and T-SPOT.TB, QFT-GIT, QFT-Plus, and LIAISON QFT-Plus were designed based on RD1-encoded antigens, such as ESAT-6 and CFP10. After reading the literature, we found $129 \mathrm{RD}$-associated antigens within the 16 RDs of $M$. tuberculosis (Ren et al., 2018). Additionally, although four antigens (Rv1737c, Rv1736c, Rv2031c, and Rv2626c) were excluded from the RD regions, previous studies have shown that these antigens show significant differences between the BCG strain and M. tuberculosis (Geluk et al., 2007; Honaker et al., 2008; Ji et al., 2015; Pena et al., 2015). Therefore, all 133 RD-associated antigens should be taken into consideration for developing new methods for the differential diagnosis of LTBI, with detailed information found in Supplementary Table 1. As mentioned above, none of these 
seven novel methods can distinguish LTBI from aTB, suggesting that the differential diagnosis method of LTBI should contain not only $\mathrm{RD}$-associated antigens but also latency-associated M. tuberculosis antigens.

Herein, we suggest that IGRAs should be further improved by the application of multiple antigens derived from RDassociated and latency-associated antigens of M. tuberculosis. Numerous studies have aimed to identify latency-associated antigens from $M$. tuberculosis as potential candidates for inclusion in immunodiagnostic tests for LTBI. A total of 124 latency-associated antigens were found in six categories-54 dormancy survival regulon antigens (DosRs), seven nutrition starvation (NS)-associated antigens, 20 reactivation antigens (RAs), five resuscitation-promoting factor (RPF) antigens, eight toxin-antitoxin system-associated antigens (TAS), and 30 other antigens associated with LTBI (Supplementary Table 2; Gordon et al., 2001; Chen et al., 2009; Ji et al., 2015; Meier et al., 2018).

Antigens belonging to both latency and RDs are the most novel and promising targets for LTBI differential diagnosis. Thus, we identified 21 LTBI-RD-related antigens from 133 $\mathrm{RD}$-associated antigens and 124 latency-associated antigens of M. tuberculosis, including Rv1736c, Rv1737c, Rv2031c, Rv2626c, Rv2653c, Rv2654c, Rv2656c, Rv2657c, Rv2658c, Rv2659c, Rv2660c, Rv1511, Rv1978, Rv1980c, Rv1981c, Rv3872, Rv3873, Rv3878, Rv3879c, Rv3425, and Rv3429 (Figure 2). Detailed information on these 21 LTBI-RD-related antigens is summarized in Table 2. In brief, (1) There are four antigens derived from DosRs and RD-others, including Rv1736c, Rv1737c, Rv2031c, and Rv2626c. Honaker et al. (2008) reported that Rv1736c and Rv1737c were induced by M. tuberculosis rather than 13 BCG strains or M. bovis, suggesting that both antigens can be used to differentially diagnose latent infection even in BCG-vaccinated individuals. Rv1737c induced higher frequencies of IFN- $\gamma^{+} \mathrm{CD} 8^{+} \mathrm{T}$ cells and IFN- $\gamma^{+}$TNF- $\alpha^{+}$ $\mathrm{CD}^{+}{ }^{+} \mathrm{T}$ cells with a CD45RO ${ }^{+} \mathrm{CD}_{2} 7^{+}$phenotype in long-term LTBI than pulmonary TB (PTB) (Arroyo et al., 2016), and the levels of the five cytokines [IL-10, transforming growth factor (TGF)- $\alpha$, TNF- $\alpha$, IL-12 (p40), and epidermal growth factor (EGF)] stimulated by Rv1737c were significantly higher in patients with TB than in household contacts (Chegou et al., 2012). For the Rv2031c antigen, it has been indicated that it could induce significantly higher IFN- $\gamma$ production in the $\mathrm{TST}^{-} / \mathrm{RD}^{+}$and $\mathrm{TST}^{+} / \mathrm{RD}^{+}$groups than in the aTB group (Araujo et al., 2015). Furthermore, in patients with long-term LTBIs, higher percentages of IFN- $\gamma^{+}$TNF- $\alpha^{+} \mathrm{CD}^{+} \mathrm{T}$ cells were found in response to Rv2031c protein in comparison with $\mathrm{PPD}^{-}$controls, with the most frequent memory phenotype of these cells being effector memory (CCR7 ${ }^{-} \mathrm{CD} 45 \mathrm{RA}^{-}$) $\mathrm{T}$ cells, followed by effector (CCR7 ${ }^{-} \mathrm{CD} 45 \mathrm{RA}^{+}$) $\mathrm{T}$ cells (Commandeur et al., 2011), which is consistent with an essential role of $\mathrm{CD}^{+} \mathrm{T}$ cells in defending the host from $M$. tuberculosis infection (Bruns et al., 2009). The Rv2626c antigen induced significantly higher levels of IFN- $\gamma$ in $\mathrm{QFT}^{+}$individuals or healthy household contacts than in $\mathrm{QFT}^{-}$individuals or patients with $\mathrm{TB}$ and had the ability to differentiate individuals with LTBI from healthy controls and patients with TB, with $78.95 \%$ sensitivity and $83.02 \%$ specificity (Prabhavathi et al., 2015; Amiano et al., 2020), which is consistent with the sensitivity

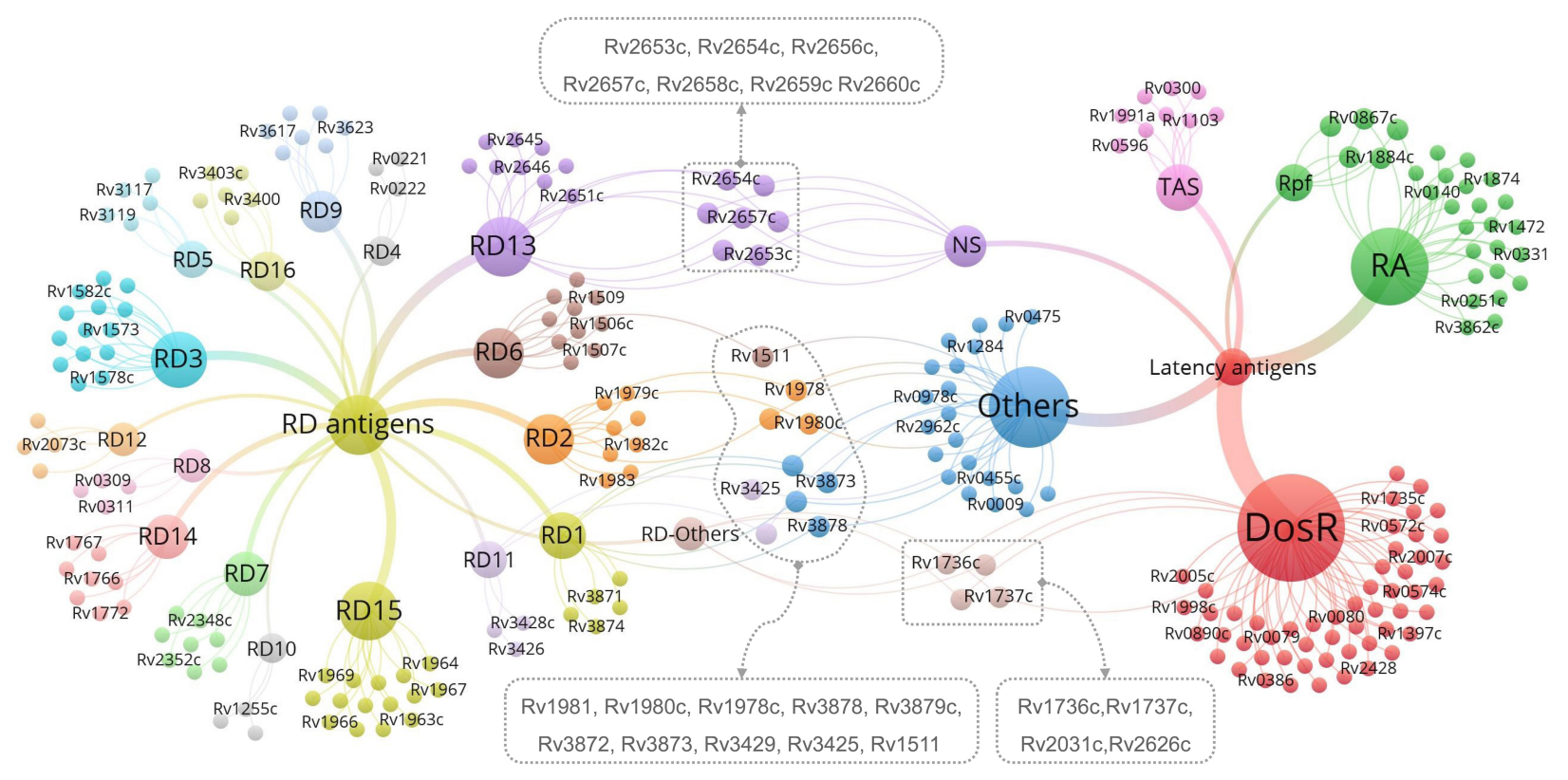

FIGURE 2 | The most promising LTBI-RD-related antigens for differential diagnosis of latent tuberculosis infection (LTBI) in the future. LTBI-related antigens are divided into six subtypes, including DosR, TAS, RA, NS, Rpf, and Others. RD-related antigens are divided into 16 subtypes, including RD1-RD15 and Others. Each subtype contains several antigens, each antigen is represented by a bubble, and different subtypes are represented by different colors. The size of the bubble represents the number of antigens in the subtype, and the line thickness represent the strength of the connection. The LTBI-RD-related antigens were identified by using a visualization and exploration software Graph (version 0.9.2, https://gephi.org/) and highlighted with dotted box. Each dot presents an antigen, limited to the space, some antigens' names were not shown in this figure, the detailed information can be found in Supplementary Tables $\mathbf{1}, \mathbf{2}$. 
TABLE 2 | Summary of the most important LTBI-RD related antigens for LTBI differential diagnosis.

\begin{tabular}{|c|c|c|c|c|c|c|c|}
\hline \multirow[t]{2}{*}{ Antigens $^{\mathrm{a}}$} & \multicolumn{2}{|c|}{ Types $^{\mathrm{a}}$} & \multirow[t]{2}{*}{ Product $^{\mathrm{b}}$} & \multirow[t]{2}{*}{ Function $^{b}$} & \multirow[t]{2}{*}{ Functional category ${ }^{b}$} & \multirow[t]{2}{*}{ LTBI differential diagnosis } & \multirow[t]{2}{*}{ References } \\
\hline & LTBI & RD & & & & & \\
\hline Rv1736c & DosR & Others & $\begin{array}{l}\text { Probable nitrate } \\
\text { reductase NarX }\end{array}$ & $\begin{array}{l}\text { Involved in nitrate reduction, and in } \\
\text { the persistence in the host }\end{array}$ & $\begin{array}{l}\text { Intermediary metabolism and } \\
\text { respiration }\end{array}$ & Induced by M. tuberculosis rather than 13 BCG strains or M. bovis & Honaker et al., 2008 \\
\hline Rv1737c & DosR & Others & $\begin{array}{l}\text { Possible nitrate/nitrite } \\
\text { transporter Nark2 }\end{array}$ & $\begin{array}{l}\text { Involved in excretion of nitrite, } \\
\text { produced by the dissimilatory } \\
\text { reduction of nitrate, across the } \\
\text { membrane. Responsible for the } \\
\text { translocation of the substrate across } \\
\text { the membrane. }\end{array}$ & Cell wall and cell processes & $\begin{array}{l}\text { (1) Higher TNF- } \alpha^{+} \mathrm{CD} 4^{+} \mathrm{T} \text { cells and IFN- } \gamma^{+} \mathrm{TNF}-\alpha^{+} \mathrm{CD} 4^{+} \mathrm{T} \text { cells in } \\
\text { LTBI vs. PTB. } \\
\text { (2) Higher IFN- } \gamma^{+} \text {TNF- } \alpha^{+} \mathrm{CD} 8^{+} \text {T cells in LTBI vs. HC }\end{array}$ & $\begin{array}{l}\text { Chegou et al., 2012; } \\
\text { Arroyo et al., } 2016\end{array}$ \\
\hline Rv2031c & DosR & Others & $\begin{array}{l}\text { Heat shock protein } \\
\text { HspX }\end{array}$ & $\begin{array}{l}\text { Has a proposed role in maintenance } \\
\text { of long-term viability during latent, } \\
\text { asymptomatic infections, and a } \\
\text { proposed role in replication during } \\
\text { initial infection. }\end{array}$ & $\begin{array}{l}\text { Virulence, detoxification, } \\
\text { adaptation }\end{array}$ & $\begin{array}{l}\text { (1) Higher IFN- }-\gamma^{+} \text {TNF- } \alpha^{+} \text {CD8 } 8^{+} \text {T cells in LTBI vs. HCs } \\
\text { (2) Higher concentrations of IFN- }- \text { in LTBI vs. aTB vs. HC } \\
\text { (3) Lower IFN- } \gamma \text {, L-10, TNF- } \alpha \text { in LTBI vs. aTB and HCs }\end{array}$ & $\begin{array}{l}\text { Commandeur et al., } \\
\text { 2011; Araujo et al., } \\
\text { 2015; Belay et al., } 2015\end{array}$ \\
\hline Rv2626c & DosR & Others & $\begin{array}{l}\text { Hypoxic response } \\
\text { protein } 1 \mathrm{Hrp} 1\end{array}$ & Unknown & Conserved hypotheticals & $\begin{array}{l}\text { (1) } 91 \% \text { of CC QFT- }{ }^{-} \text {subjects secreted low levels of IFN- } \gamma \text {, but } 43 \% \text { of } \\
\text { HCWs QFT- people produced elevated IFN- }-6,69 \% \text { of CC QFT } \\
\text { subjects didn't produce IFN- } \gamma \text { to Rv2626c } \\
\text { (2) Higher IFN- }-\gamma \text { producing T cells in CC vs. aTB and HC } \\
\text { (3) IFN- } \gamma \text { response to Rv2626c has shown positivity of } 88.57 \% \text { in CC } \\
\text { and } 7.5 \% \text { in PTB } \\
\text { (4) Sensitivity and specificity of Rv2626c in aTB was of } 77.1 \% \text { and } \\
85.1 \%\end{array}$ & $\begin{array}{l}\text { Ashraf et al., 2014; } \\
\text { Prabhavathi et al., } \\
\text { 2015; Amiano et al., } \\
2020\end{array}$ \\
\hline Rv2653c & NS & $\mathrm{RD}-13$ & $\begin{array}{l}\text { Possible PhiRv2 } \\
\text { prophage protein }\end{array}$ & Unknown & Insertion seqs and phages & $\begin{array}{l}\text { Less reactive DTH skin responses in } M \text {. tuberculosis-sensitized guinea } \\
\text { pigs vs. PPD, but elicited no response in BCG-vaccinated guinea pigs. }\end{array}$ & $\begin{array}{l}\text { Kasempimolporn et al., } \\
2019\end{array}$ \\
\hline Rv2654c & NS & RD-13 & $\begin{array}{l}\text { Possible PhiRv2 } \\
\text { prophage protein }\end{array}$ & Unknown & Insertion seqs and phages & $\begin{array}{l}\text { (1) Higher IFN- } \gamma \text { levels TB vs. HC, had a high overall agreement (98.0\%) } \\
\text { with T-SPOT.TB, the combination of Rv2645 and CFP10-ESAT6 } \\
\text { increased sensitivity and specificity of } 96.0 \% \text { and } 98.2 \% \text {, respectively. } \\
\text { (2) Peptide Rv2654C } 51-65 \text { boosted the quantitative performance of the } \\
\text { QFT-GIT assay from } 1.83 \mathrm{IU} / \mathrm{ml} \text { to } 2.83 \mathrm{IU} / \mathrm{ml}\end{array}$ & $\begin{array}{l}\text { Luo et al., 2015; } \\
\text { Horvati et al., } 2016\end{array}$ \\
\hline Rv2656c & NS & RD-13 & $\begin{array}{l}\text { Possible PhiRv2 } \\
\text { prophage protein }\end{array}$ & Unknown & Insertion seqs and phages & Unknown & - \\
\hline Rv2657c & NS & $\mathrm{RD}-13$ & $\begin{array}{l}\text { Probable PhiRv2 } \\
\text { prophage integrase }\end{array}$ & Unknown & Insertion seqs and phages & $\begin{array}{l}\text { Rv2657c react with the sera from LTBI Guinea pigs but not healthy } \\
\text { Guinea pigs, SFCs of HCWs was significantly higher in HCWs vs. aTB }\end{array}$ & Yang, 2018 \\
\hline Rv2658c & NS & RD-13 & $\begin{array}{l}\text { Possible prophage } \\
\text { protein }\end{array}$ & Unknown & Insertion seqs and phages & Unknown & \\
\hline Rv2659c & NS & $\mathrm{RD}-13$ & $\begin{array}{l}\text { Probable PhiRv2 } \\
\text { prophage integrase }\end{array}$ & $\begin{array}{l}\text { Sequence integration. Integrase is } \\
\text { necessary for integration of a phage } \\
\text { into the host genome by site-specific } \\
\text { recombination }\end{array}$ & Insertion seqs and phages & Higher IFN- $\gamma$ producing $T$ cells in LTBI vs. aTB and HC & Bai, 2015 \\
\hline Rv2660c & NS & RD-13 & Hypothetical protein & Unknown & Conserved hypotheticals & 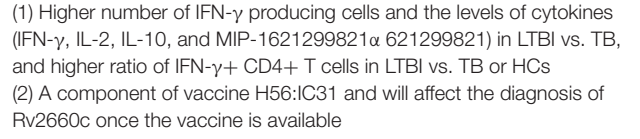 & $\begin{array}{l}\text { He et al., 2015; } \\
\text { Luabeya et al., } 2015\end{array}$ \\
\hline Rv1511 & Others & $\mathrm{RD}-6$ & $\begin{array}{l}\text { GDP-D-mannose } \\
\text { dehydratase GmdA }\end{array}$ & $\begin{array}{l}\text { Unknown, probably involved in } \\
\text { nucleotide-sugar metabolism }\end{array}$ & $\begin{array}{l}\text { Intermediary metabolism and } \\
\text { respiration }\end{array}$ & Unknown & - \\
\hline Rv1978 & Others & $\mathrm{RD}-2$ & Conserved protein & Unknown & Conserved hypotheticals & $\begin{array}{l}\text { ELISPOT of Rv } 1978 \text { achieved sensitivities of } 59 \% \text { in aTB and } \\
\text { specificities of } 94 \% \text { in BCG-vaccinated HC. }\end{array}$ & Chen et al., 2009 \\
\hline Rv1980c & Others & $\mathrm{RD}-2$ & $\begin{array}{l}\text { Immunogenic protein } \\
\text { Mpt64 }\end{array}$ & Unknown & Cell wall and cell processes & $\begin{array}{l}\text { Sensitivity and specificity were } 0.92 \text { and } 0.95 \text {, respectively, sensitivity of } \\
\text { the MPT64 test was significantly higher in TB infected children than in } \\
\text { adults. }\end{array}$ & Cao et al., 2021 \\
\hline Rv1981c & Others & RD-2 & $\begin{array}{l}\text { Ribonucleoside- } \\
\text { diphosphate reductase } \\
\text { (beta chain) NrdF1 }\end{array}$ & $\begin{array}{l}\text { Involved in the DNA replication } \\
\text { pathway. }\end{array}$ & Information pathways & $\begin{array}{l}\text { ELISPOT of Rv1981c achieved sensitivities of 60\% in aTB and } \\
\text { specificities of } 90 \% \text { in BCG-vaccinated HC. }\end{array}$ & Chen et al., 2009 \\
\hline
\end{tabular}




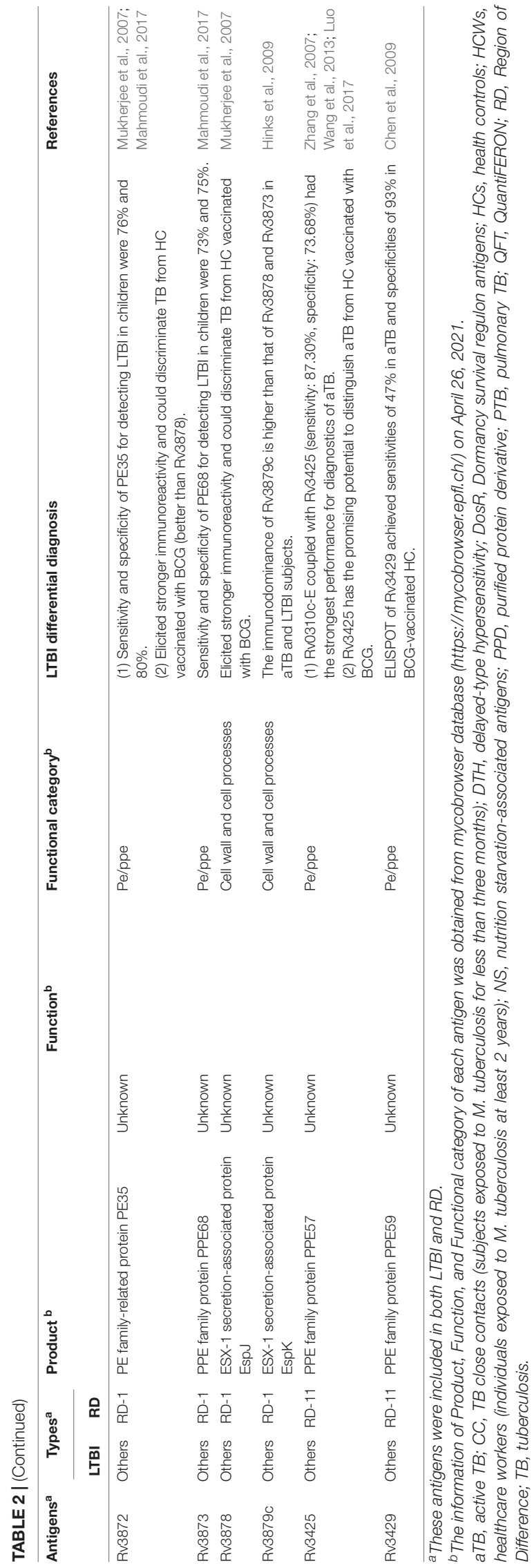

(77.1\%) and specificity (85.1\%) of Rv2626c reported in another study (Ashraf et al., 2014).

(2) Seven antigens belonging to both NS-associated antigens and RD13 exhibit considerable potential, including Rv2653c, Rv2654c, Rv2656c, Rv2657c, Rv2658c, Rv2659c, and Rv2660c. Among the seven antigens, Rv2654c and Rv2660c were the most studied antigens. A previous study showed that Rv2654c induced a higher IFN- $\gamma$ level in patients with TB than in healthy controls (HCs) and had a high overall agreement with T-SPOT.TB (98.0\%) (Luo et al., 2015). An additional study reported that peptide Rv2654c $c_{51-65}$ boosted the quantitative performance of the QFTGIT assay from $1.83 \mathrm{IU} / \mathrm{ml}$ to $2.83 \mathrm{IU} / \mathrm{ml}$ (Horvati et al., 2016). $\mathrm{Rv} 2660 \mathrm{c}$ is one of the most promising antigens for the differential diagnosis of LTBI. He et al. (2015) found that Rv2660c induced a significantly higher number of IFN- $\gamma$-producing cells and levels of cytokines [IFN- $\gamma$, IL-2, IL-10, and macrophage inflammatory protein 1-alpha (MIP-1 $\alpha$ )] in patients with LTBI than in patients with TB and a higher ratio of IFN- $\gamma^{+} \mathrm{CD}^{+} \mathrm{T}$ cells in the LTBI group than in the aTB or HC group. Moreover, it is important to note that although Rv2660c induced a stronger immune response in LTBI than in aTB, it is a component of vaccine H56:IC31, which affects the differential diagnosis of Rv2660c once the vaccine is available (Luabeya et al., 2015). Rv2653c was used as a diagnostic skin test reagent in comparison with a standard PPD, and it was found that this antigen stimulated less of a delayed-type hypersensitivity (DTH) reaction in M. tuberculosis-sensitized guinea pigs, but no response was observed in BCG-vaccinated guinea pigs (Kasempimolporn et al., 2019), suggesting that this antigen can eliminate the interference of BCG vaccination with test results. Our previous study showed that Rv2657c reacted with the sera from LTBI guinea pigs but not those of healthy guinea pigs and that the number of IFN- $\gamma$-producing cells induced by Rv2657c and Rv2659c was significantly higher in patients with LTBI than in patients with aTB or HCs (Bai, 2015; Yang, 2018), indicating that Rv2657c and Rv2659c might be promising antigens for the differential diagnosis of LTBI. Additionally, the roles of Rv2656c and Rv2658c in the differential diagnosis of LTBI are unknown.

(3) Ten antigens belong to both LTBI others and RDs, including four antigens in LTBI others-RD1 (Rv3872-Rv3879), three antigens in LTBI others-RD2 (Rv1978, Rv1980c, and Rv1981c), one antigen in LTBI others-RD6 (Rv1511), and two antigens in LTBI others-RD11 (Rv3425 and Rv3429). Among them, the antigen that is most frequently studied is Rv3872. Previous studies have reported that the sensitivity and specificity of Rv3872 for detecting LTBI in children were $76 \%$ and $80 \%$, respectively, which could elicit a stronger immunoreactivity for discriminating TB from HCs in patients who have received BCG vaccination (Mukherjee et al., 2007; Mahmoudi et al., 2017). In contrast, the remaining antigens (Rv3879, Rv1978, Rv1980c, Rv1981c, Rv3425, and Rv3429) were only tested between patients with TB and HCs with BCG vaccination or LTBI and HCs with BCG vaccination (Mukherjee et al., 2007; Zhang et al., 2007; Chen et al., 2009; Hinks et al., 2009; Wang et al., 2013; Luo et al., 2017; Mahmoudi et al., 2017; Cao et al., 2021). Hinks et al. (2009) compared the responses to a range of RD1-encoded antigens (ESAT-6, CFP-10, Rv3879c, Rv3878, Rv3873, and Rv2031c) and 
defined a similar hierarchy of immunodominance for these antigens in both aTB and LTBI subjects: CFP-10 > ESAT$6>\operatorname{Rv} 3879 c>\operatorname{Rv} 3878>\operatorname{Rv} 3873>$ Rv2031c. Furthermore, Rv3425 has been evaluated as a candidate for the development of a vaccine for TB control, which may affect its accuracy in detecting LTBI (Wang et al., 2008).

Our findings suggest that these 21 LTBI-RD-associated antigens are promising alternatives to diagnostic biomarkers for discriminating LTBI from aTB and HCs in patients who have received BCG vaccination. By analyzing the above research results, it is not difficult to find that the intensity of the immune response induced by these LTBI-RD-related antigens was always higher in the LTBI group than in the aTB group. However, the ESAT-6/CFP10 responses, which are not dormancy related, were also much higher in the LTBI group than in the aTB group; thus, the relative advantages of these LTBI-RD-related antigens are unclear. The reason for this may be as follows: the immunity of patients with aTB is weakened and the responses of $\mathrm{T}$ cells are usually suppressed (Figure 1A). Therefore, the sensitivity and specificity of these LTBI-RD-related antigens need to be validated in further studies with larger sample sizes and broader population coverage in the future. In addition, there are also problems in the differential diagnosis of LTBI-RD-associated antigens: (1) the immunogenicity of these antigens is significantly lower than that of proliferative antigens; (2) the population coverage rate of the immune responses induced by these antigens is low; (3) most of the M. tuberculosis in the macrophages of patients with LTBI are in a state of latent infection, but a small part of them is in a state of irregular proliferation; and (4) not all M. tuberculosis in patients with active $\mathrm{TB}$ are in a proliferative state and are influenced by the immune state of the host and the treatment of chemotherapy drugs, with some M. tuberculosis possibly also being in a latent state.

\section{Peptides}

The LTBI-RD-associated antigens derived from M. tuberculosis constitute a potential source of specific antigens for immunodiagnosis and vaccine development for LTBI. Screening the diagnostic potential of specific T- or B-cell epitopes from LTBI-RD-associated antigens and verifying their peptides in different populations are a new concept for the differential diagnosis of LTBI. Currently, most of the studies on peptides derived from LTBI-RD-related antigens in differentiating LTBI from aTB and HCs are still in their initial stages. Only a few studies have screened immunodominant peptides of latency and/or RD-related antigens in animal models and humans, such as Rv1985 $c_{\text {pool2 }}, R_{19} 198 c_{\text {pool4 }}$, Rv3425 pool1 (Wang et al., 2013), Rv1733c57-84 (Coppola et al., 2015), Rv2654c51-65 (Horvati et al., 2016), peptide pools from RD1 antigens (Rv3871 to Rv3878) (Mustafa et al., 2002), T-cell epitopes of Rv3872 and Rv3873 (Hanif et al., 2011; Jiang et al., 2016), and Rv3425118-126 (LIASNVAGV) (Chen et al., 2012). However, most of these mapped and identified peptides can only discriminate aTB from HCs with BCG vaccination and fail to distinguish LTBI from aTB.

The limitation of these studies is that they only focused on epitopes singly identified from $\mathrm{CD}^{+} \mathrm{T}$ lymphocytes [helper $\mathrm{T}$ lymphocytes (Th)] or $\mathrm{CD}^{+} \mathrm{T}$ lymphocytes (CTLs) rather than epitopes synchronously identified from Th cells, CTL cells, and $\mathrm{B}$ cells. Although the traditional view is that the host clearance and killing of $M$. tuberculosis mainly depend on $\mathrm{CD}_{4}^{+}$ T lymphocytes and CD8 ${ }^{+}$T lymphocytes, accumulated data show that B lymphocytes also play an irreplaceable role in fighting against M. tuberculosis (Gong et al., 2018, 2021; Watson et al., 2021). Therefore, peptides binding to Th cells, CTL cells, and $\mathrm{B}$ cells should be considered when designing new candidate biomarkers based on epitopes for distinguishing LTBI from aTB and BCG-vaccinated HCs.

Furthermore, MHC molecules affect the efficacy of peptidebased vaccines and diagnosis (Gong et al., 2021; Jia et al., 2021). It is well known that recognition peptides produced by $\mathrm{CD}^{+}$ or $\mathrm{CD}^{+} \mathrm{T}$ cells are mostly restricted to MHC-II or MHC-I molecules, respectively. Human leukocyte antigens (HLAs) are highly polymorphic; thus, the selection of peptides that can be recognized by multiple HLAs will increase the population coverage of peptide-based diagnosis (Bui et al., 2006). As the frequency of HLA expression varies greatly among different ethnicities, the problem of population coverage related to MHC polymorphisms becomes more complicated. Thus, without careful consideration, peptide-based vaccines or diagnostic candidates will result in ethnically biased population coverage.

\section{Novel Biomarkers Derived From Hosts}

Our previous research and other large amounts of data show that TB is not only an infectious disease but also an immune disease (Gong et al., 2018, 2020, 2021; Li et al., 2020; Liang et al., 2021; Rambaran et al., 2021). The pathogenesis of TB is closely related to the host's immune response. Therefore, to promote the development of sensitive methods for the detection and treatment of LTBI, it is particularly urgent to understand the host responses involved in the establishment and maintenance of LTBI (Banerjee et al., 2021).

\section{Cytokines}

Cytokines are small molecular polypeptides or glycoproteins synthesized and secreted by immune cells (such as monocytes, macrophages, T cells, B cells, and NK cells) and some non-immune cells (such as endothelial cells, epidermal cells, and fibroblasts) after stimulation. Cytokines have a variety of biological functions, such as regulation of cell growth, differentiation and maturation, immune response, inflammation, wound healing, tumor growth, and function maintenance. Levels of host cytokines vary in the different stages of $M$. tuberculosis infection, which may serve as biomarkers for differentiating LTBI from aTB (Luo et al., 2019).

Detection of IFN- $\gamma$ stimulated by specific antigens of M. tuberculosis is a common practice in most IGRA experiments. Won et al. (2017) measured the levels of 29 cytokines in 48 patients with aTB, $15 \mathrm{LTBI}$, and $13 \mathrm{HCs}$ and found that eight cytokines [GM-CSF, IFN- $\gamma$, IL-1RA, IL-2, IL-3, IL-13, interferongamma-inducible protein 10 (IP-10), and MIP-1 $\beta$ ] in the TBinfected group were significantly different from those of the HCs, and that eight cytokines [EGF, GM-CSF, IFN- $\gamma$, IL-2, IL5, IL-10, TNF- $\alpha$, and vascular endothelial growth factor (VEGF)] were significantly different between aTB and LTBI. However, the 
limitation of this study is its small sample size, with its results needing to be further verified through another study with a large sample size. In 2018, Meier et al. (2018) performed a systematic review to summarize the cytokines measured in 34 included studies, with as many as 26 cytokines used as biomarkers in these studies, including IFN- $\gamma$, TNF- $\alpha$, IL-2, IL-10, IL-17, IL-8, IL-6, IP-10, IL-1 $\beta$, monocyte chemoattractant protein-1 (MCP-1), IL12, IL-12p40, MCP-2, fractalkine, granzyme B, GM-CSF, IFN- $\alpha 2$, sIL-2Ra, IL-4, IL-5, IL-13, MIP-1 $\beta$, Regulated upon Activation, Normal T cell Expressed and presumably Secreted (RANTES), sCD40L, TGF- $\alpha$, and VEGF. Among these 26 cytokines, the top 5 cytokines used as biomarkers for discriminating between LTBI and patients with aTB were IFN- $\gamma$ (34 publications), TNF- $\alpha$ (15 publications), IL-2 (12 publications), IL-10 (10 publications), and IL-17 (9 publications) (Supplementary Figure 1).

Although IFN- $\gamma$ and TNF- $\alpha$ are still the most popular cytokines in the differential diagnosis of LTBI, studies on IL-2, IL-10, IP-10, and VEGF have been increasing in recent years. To understand the latest research progress on these cytokines for discriminating between LTBI and aTB, we searched publications related to them in the Web of Science database. We found that the number of publications related to IFN- $\gamma$, TNF- $\alpha$, IL-2, IL-10, IP10 , and VEGF were $1,419,418,136,62,96$, and 18 , respectively (Figure 3). The co-authorship map of IFN- $\gamma$ (Figure 3A), TNF- $\alpha$ (Figure 3B), IL-2 (Figure 3C), IL-10 (Figure 3D), IP10 (Figure 3E), and VEGF (Figure 3F) cytokines based on bibliographic data showed similar trends and popularity to the systematic review. In 2020, two meta-analyses were conducted to evaluate candidate cytokines as biomarkers to distinguish LTBI infection from aTB. A systematic meta-analysis by Sudbury et al. (2020) measured 100 cytokines among 56 included studies and found that the most frequently studied cytokines were IFN- $\gamma$, IL2, TNF- $\alpha$, IP-10, IL-10, and IL-13. A meta-analysis by Qiu et al. (2020) evaluated seven cytokines, including IFN- $\gamma$, TNF- $\alpha$, IP10, IL-2, IL-10, IL-12, and VEGF, suggesting that cytokines IL-2, IFN- $\gamma$, and VEGF can be utilized as promising biomarkers to distinguish LTBI from aTB. Furthermore, compared to IFN- $\gamma$, the level of IP-10 was higher and was released independently of age, suggesting that IP-10 may be a candidate biomarker in the pediatric population (Alsleben et al., 2012).

Although individual cytokines provide considerable potential for use in the differential diagnosis of LTBI, for most cytokines, findings were heterogeneous among studies. These differences in results or even diametrically opposite conclusions may be related to differences in study design, experimental methods, statistical methods, individual genetic backgrounds, antigen types, sample sizes, and environmental factors (Rambaran et al., 2021). Therefore, reducing or even eliminating the heterogeneity between different research results is a limitation that needs to be overcome. Recent studies have found that a combination of cytokines may be an alternative to solve this problem. Wang et al. (2018) identified a six-cytokine biosignature (including IFN$\gamma$, IL-10, IL-1Ra, IP-10, VEGF, and IL-12p70) to discriminate between aTB and LTBI, resulting in a sensitivity of $88.2 \%$ and a specificity of $92.1 \%$ in a biomarker validation cohort $(n=216)$ and a sensitivity of $85.7 \%$ and a specificity of $91.3 \%$ in a prospectively recruited clinical validation cohort $(n=194)$, respectively. Coincidentally, Korma et al. (2020) evaluated the sensitivity, specificity, and accuracy of the combination of seven cytokines (IFN- $\gamma$, IP-10, IL-2R, C-X-C Motif Chemokine Ligand 9 (CXCL-9), IL-10, IL-4, and TNF- $\alpha$ ) based on gene expression in differentiating between aTB and LTBI. They demonstrated that the combination of IL-10, IP-10, and IL- 4 could differentiate pulmonary patients with TB from latent patients with TB with a sensitivity and specificity of $77.1 \%$ and $88.1 \%$, respectively (Korma et al., 2020). Luo et al. (2019) identified potential biomarkers from 38 plasma cytokines to discriminate among the different stages of $M$. tuberculosis infection in its study participants, who were composed of 78 patients with aTB, 73 patients with LTBI, and $76 \mathrm{HCs}$. They found that the combination of five cytokines (IP-10, MCP-1, IL-1 $\alpha$, IL-10, and TNF- $\alpha$ ) had an excellent performance in diagnosing LTBI, with 94\% sensitivity and $81.25 \%$ specificity, and that the combination of three cytokines (eotaxin, macrophage-derived chemokine (MDC), and MCP-1) had a 0.94 area under the curve (AUC) in differentiating ATB from LTBI with $87.76 \%$ sensitivity and $91.84 \%$ specificity, respectively (Luo et al., 2019). The above data show that the combination of multiple cytokines can significantly improve specificity and sensitivity, which also points out the direction of future research.

\section{Antibodies}

Antibody responses are a major form of defense against microbes (Vinuesa et al., 2016). M. tuberculosis infection has been reported to induce antibody responses, but it is still unclear whether patients with aTB or those with LTBI produce protective antibodies, as well as which antigens these target (Feng et al., 2013; Loxton and van Rensburg, 2021). With the emerging evidence regarding immune modulation, the complete characterization of $\mathrm{B}$ cells and humoral immunity could be of significant value (Dubois Cauwelaert et al., 2016). In 2013, Feng et al. (2013) developed a novel 38F-64F indirect ELISA (including $38 \mathrm{kDa}$, ESAT-6, CFP10, Mtb8.4, MPT64, TB16.3, and Mtb8) method to detect TB and LTBI, and the results showed that the sensitivity of the 38F-64F indirect ELISA was much higher than that of the sputum culture test $(86.91 \%$ vs. $50.62 \%)$, with the sensitivity of the sputum smear test $(78.64 \%$ vs. $47.57 \%$ ) accounting for $74.16 \%$ and $37.14 \%$ of patients with TB and patients with LTBI, respectively. Five years later, a study screened serum biomarkers of 40 serum samples from patients with LTBI and aTB using a proteome microarray containing 4,262 antigens, and the results suggested that specific IgG levels of 152 M. tuberculosis antigens were significantly higher in patients with aTB than in LTBI (Cao et al., 2018). However, any single antigen-specific antibody is not enough to be used to cover the antibody profiles of all patients with TB. Therefore, the combination of antigen-specific antibodies may be an alternative for increasing sensitivity and specificity. Yan et al. (2018) reported that the sensitivity and specificity of individual antigen-specific antibodies are relatively low in detecting patients with TB not infected with the bacteria, but the combination of six antigenspecific antibodies (LAM, 38KD, MPT32, EspC, MPT64, and Mtb81) increased sensitivity and specificity to $69.6 \%$ and $77.0 \%$, respectively. Similarly, another study also demonstrated that 

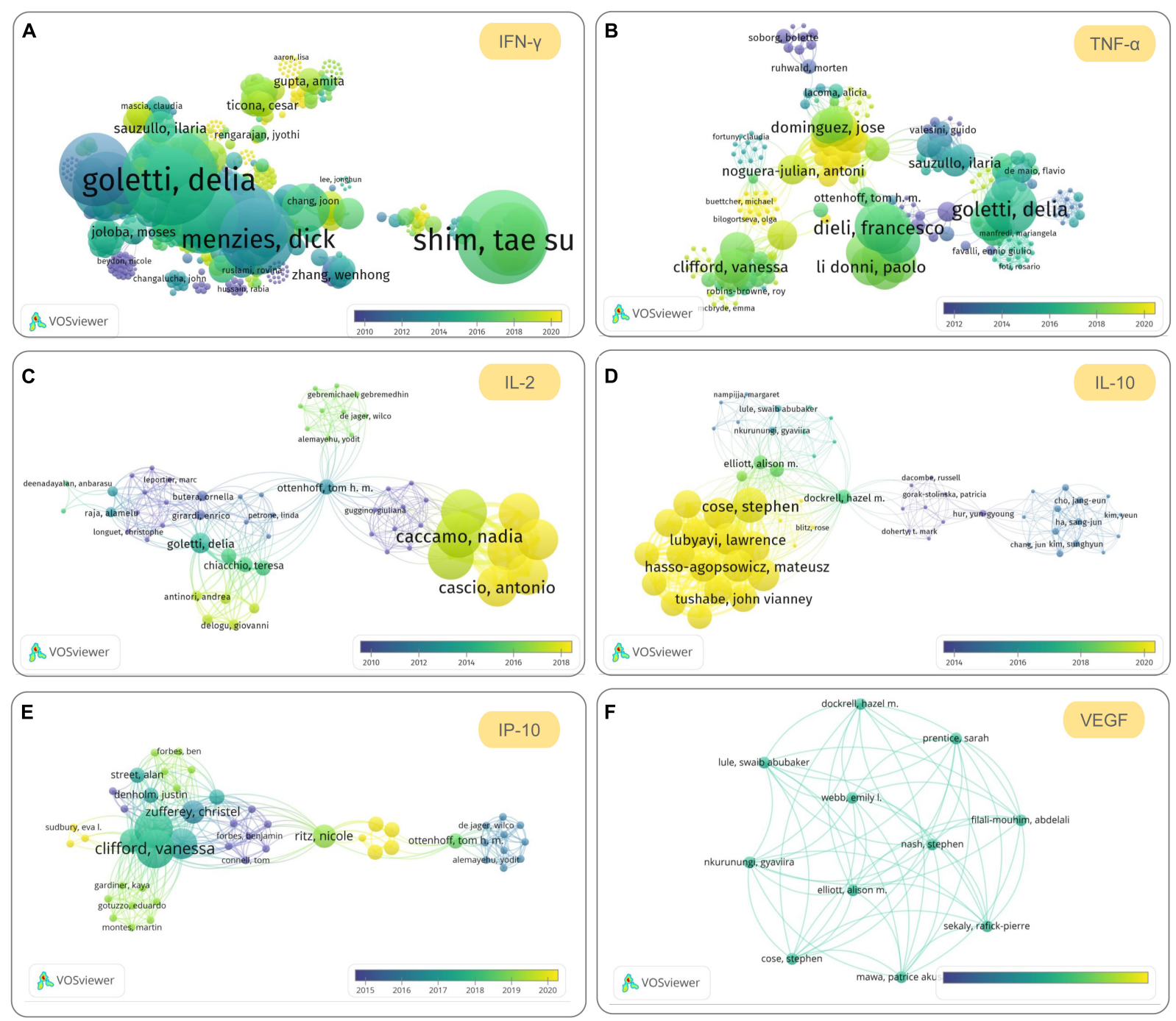

FIGURE 3 | The most promising cytokines to be used to differentiate and diagnose latent tuberculosis infection (LTBI) in the future. The co-authorship maps of interferon (IFN)- $\gamma$ (A), tumor necrosis factor (TNF)- $\alpha$ (B), interleukin (IL)-2 (C), IL-10 (D), interferon-gamma-inducible protein 10 (IP-10) (E), and vascular endothelial growth factor (VEGF) (F) cytokines based on bibliographic data obtained from Web of Science were visualized by using VoSviewer version 1.6.16 (developed by Nees Jan van Eck and Ludo Waltman at Leiden University's Centre for Science and Technology Studies CWTS). The search terms used in Web of Science are "LTBI" and cytokine name (topic terms), the Timespan was set from 1900 to 2021, the database was set "All databases," and other parameters are default values. The parameters in VOSviewer were set as below: Type of analysis, Co-authorship; Unit of analysis, Authors; Counting method, Full counting; Normalization method, Association strength; Layout, Attractions 2, Repulsion-1; Clustering, Resolution 1.00, Min. cluster size 1; other parameters are default values.

the sensitivity (96.6\%) and specificity (92.3\%) of IgA/IgG of a fused MT10.3:MPT64 protein were significantly higher than those of single antigens in pleural TB cases (da Silva et al., 2019). These results suggest that combining multiple antigenspecific antibodies can significantly improve the sensitivity and specificity of a single antigen-specific antibody, which will help in the diagnosis of TB and LTBI, but the current data are insufficient and further research is needed.

\section{Markers of Immune Cells}

As mentioned above, TB is a heterogeneous disease with a wide range of infectious and immunological profiles. It is well-known that the immunological markers of T-lymphocyte subsets and
NK cell surfaces correlate with cell differentiation, latency/disease status, and outcome, making these cell surface markers potential targets for TB diagnosis and treatment (Petruccioli et al., 2016).

$\mathrm{CD} 4^{+} \mathrm{T}$ lymphocytes play a fundamental role in controlling $M$. tuberculosis infection, and the biomarker expression profiles of $\mathrm{CD}^{+} \mathrm{T}$ cell surfaces are associated with bacterial loads at different infection stages. Assessment of CD27 and/or CCR4 expression on $\mathrm{CD} 4^{+} \mathrm{T}$ cells has been reported to be a robust biomarker for discriminating among TB stages. A previous study analyzed the expression of CD27 and CCR4 biomarkers in IFN- $\gamma^{+} \mathrm{CD}^{+} \mathrm{T}$ cells collected from patients with aTB and patients with LTBI and found that the proportion of $\mathrm{CD} 27^{-} \mathrm{IFN}-\gamma^{+} \mathrm{CD} 4^{+} \mathrm{T}$ cells or $\mathrm{CCR} 4^{+} \mathrm{IFN}-\gamma^{+} \mathrm{CD} 4^{+} \mathrm{T}$ cells 
was significantly higher in patients with aTB than in those with LTBI in response to PPD or ESAT-6/CFP-10 recombinant proteins and that the proportion of $\mathrm{CD} 27^{-} \mathrm{CCR} 4^{+} \mathrm{IFN}-\gamma^{+} \mathrm{CD} 4^{+}$ $\mathrm{T}$ cells was significantly associated with aTB. Furthermore, other studies also found that the $\mathrm{CD} 38^{+} \mathrm{CD} 27^{-} \mathrm{TNF}-\alpha^{+} \mathrm{CD} 4^{+} \mathrm{T}$-cell subset is a potential biomarker for diagnosing TB with $96.15 \%$ specificity and $90.16 \%$ sensitivity (Acharya et al., 2021), with IFN$\gamma^{+} \mathrm{CD} 27^{\text {low }} \mathrm{CD} 4{ }^{+} \mathrm{T}$ cells described as aTB biomarkers (Latorre et al., 2018). These findings suggest that the loss of CD27 and the increase in CD38 and CCR4 biomarkers could be associated with uncontrolled $M$. tuberculosis infection. In addition, innate $\mathrm{T}$ cells, such as MAIT and invariant NK T (iNKT) cells, play roles in recognizing $M$. tuberculosis-infected cells. Accumulating evidence highlights the importance of both MAIT and iNKT cells in controlling TB infection (Ruibal et al., 2021). It has been reported that the number of both cell types was significantly higher in subjects with LTBI than in patients with aTB or uninfected individuals, and that iNKT cells from patients with LTBI showed lower PD-1 expression than those from patients with aTB (Paquin-Proulx et al., 2018).

\section{New Models and Algorithms}

As mentioned above, the immunological methods that are frequently used, such as skin tests and IGRAs, are intrinsically unable to discriminate LTBI from aTB. Recently, with the development of artificial intelligence (AI) and bioinformatics, new strategies have been introduced to improve diagnostic performance in distinguishing LTBI from aTB, such as the ImmunoScore (IS) model, Cox proportional hazards model, expectation maximization algorithm, silico mapping algorithm, and random forest algorithm (Villate et al., 2006; Zhou et al., 2017; Ndzi et al., 2019; Wu et al., 2019; Rambaran et al., 2021). IS is a novel and promising prognostic tool that is widely used in tumors. It has been reported that the IS model can effectively distinguish aTB from LTBI, with a sensitivity of $95.7 \%$ and a specificity of $92.1 \%$ (Zhou et al., 2017). The Cox proportional hazards model was applied to estimate the survival experience and risk factors among patients with $\mathrm{TB}$, and these studies observed that associations were stronger in the Cox proportional hazards model, suggesting that the impact of behavioral and clinical variables affected TB outcome (Tolosie and Sharma, 2014; Abedi et al., 2019; Rambaran et al., 2021). Villate et al. (2006) analyzed infection data of LTBI and M. avium using the expectation maximization algorithm, and their results confirmed that the mixture models using the expectation maximization algorithm can better estimate the probability of LTBI in the presence of other NTM and BCG vaccinations. Ndzi et al. (2019) developed a silico mapping algorithm to discriminate LTBI from aTB and found that people with the QFT-GIT ${ }^{+}$and DRB1*10$\mathrm{DQB1}^{*} 02$ haplotype ${ }^{+}$may have a higher chance of developing LTBI and that those with the QFT-GIT ${ }^{+}$and DRB1* $10-\mathrm{DQB} 1^{*} 02$ haplotype ${ }^{-}$may progress to aTB. Wu et al. (2019) also developed a random forest algorithm to discriminate between aTB and LTBI based on the test data of T-SPOT.TB, and the results indicated that the sensitivity and specificity of this algorithm were $82.87 \%$ and $88.03 \%$, respectively, which were higher than those of $\mathrm{T}$ SPOT.TB $(82.80 \%$ and $70.00 \%$, respectively), TB $(82.80 \%$ and
74.20\%), and QFT-GIT (71.40\% and 81.00\%). Although these innovative strategies are still in their initial development stages with only a few studies conducted on them, they still provide valuable information for a comprehensive understanding of TB and allow for new insights on differential diagnosis of LTBI and aTB to be gained.

\section{Omics Technologies}

In recent years, advances in multiplexing and information technology have enabled researchers to perform more comprehensive analyses of complete genomes, transcriptomes, proteomes, and metabolomes. The use of these omics techniques has provided valuable insights for understanding the transcriptomic, proteomic, and metabolomic changes of M. tuberculosis during dormancy and reactivation.

\section{Transcriptomics}

The complete genome sequencing of the M. tuberculosis $\mathrm{H} 37 \mathrm{Rv}$ strain in 1998 allowed for improvement in our understanding of M. tuberculosis (Cole et al., 1998). Transcriptome analysis provides insights into the expression profiles of genes in human samples (such as blood) during the different stages of M. tuberculosis infection. As early as 2007, Jacobsen et al. (2007) compared the gene expression signature of peripheral blood mononuclear cells (PBMCs) collected from patients with aTB, individuals with LTBI, and HCs by microarray analysis and found that three genes (Ras-associated GTPase 33A, lactoferrin, and CD64) were sufficient for classifying these three groups of individuals. Almost at the same time, Mistry et al. (2007) expanded the application of this technology to patients with aTB and individuals with LTBI in patients with recurrent disease and cured patients with TB using DNA array technology and quantitative reverse-transcriptase polymerase chain reaction (qRT-PCR). Their results demonstrated that a set of nine genes could discriminate the four groups of individuals, including ATP5G1, ASNA1, C14orf2, KIAA2013, LY6G6D, NOLA3, RIN3, SOCS3, and TEX264. Zhang et al. (2007) determined the transcriptomic profiles of exosomal RNAs collected from 30 HCs, 30 patients with aTB, and 30 individuals with LTBI. In comparison with the HCs, five genes were significantly upregulated and highly expressed in individuals with LTBI, but they were downregulated and expressed at low levels in patients with aTB. These included TTLL10, RP11-358N4.3, $R M R P, P P P H 1$, and RN7SK (Lv et al., 2017), which represent novel biomarkers for the diagnosis of LTBI and aTB. More recently, Bayaa et al. (2021) conducted a multicenter prospective nested case-control study to evaluate the performance of a human blood transcriptomic signature termed RISK6 in the diagnosis of LTBI and aTB, and their results showed that the sensitivity and specificity of RISK6 for discriminating aTB from LTBI were $90.9 \%$ and $88.5 \%$, respectively.

Transcriptomics is also used to assess the risk of LTBI developing into aTB. In 2010, a study analyzed the genome-wide transcriptional profiles of blood samples obtained from patients with aTB, individuals with LTBI, and HCs and found that the signatures of aTB were observed in $10 \%-20 \%$ of patients with 
LTBI, indicating that these identified individuals with LTBI were at risk of developing aTB (Berry et al., 2010).

\section{Proteomics}

Proteomics, developed on the basis of genomics, is complementary to studies at the transcriptional level (Betts, 2002). The emergence and development of proteomics have enabled the discovery of new biomarkers at the gene level, which can be used to distinguish LTBI from aTB to be verified at the protein level. Previous studies have identified a large number of biomarkers that are differentially regulated during dormancy and reactivation using proteomics and transcriptomics; for example, the DosR and genes involved in DNA replication are upregulated and downregulated, respectively, during dormancy, but undergo the opposite changes during reactivation (Kundu and Basu, 2021). Cao et al. (2018) performed a proteome microarray assay containing 4,262 antigens to identify potential serum biomarkers for distinguishing between LTBI and aTB, and their results indicated that antigens Rv2031c, Rv1408, and Rv2421c had higher AUCs of $0.8520,0.8152$, and 0.7970 , respectively. With the development of high-resolution quantitative proteomics and label-free quantitative proteomics, a growing number of protein signatures that can be used for the differential diagnosis of LTBI and aTB have been discovered. Mateos et al. (2019) performed high-resolution quantitative proteomics using an LTQ-OrbitrapElite platform to screen for potential protein signatures in the sputum and saliva of patients with aTB, individuals with LTBI, and HCs. Their findings suggested that a reduction in proteins related to glucose and lipid metabolism was observed in the saliva of patients with $\mathrm{TB}$, while the proteomic signatures of sputum from individuals with LTBI and HCs consisted of proteins related to bitterness perception, pathogen defense, and the innate immune response. Similarly, Sun et al. (2018) performed label-free quantitative proteomics to determine plasma signatures for discriminating PTB from LTBI or HCs and found that a combination of alpha-1-antichymotrypsin (ACT), alpha-1-acid glycoprotein 1 (AGP1), and E-cadherin (CDH1) showed $81.2 \%$ sensitivity and $95.2 \%$ specificity in discriminating PTB from LTBI and $81.2 \%$ sensitivity and $90.1 \%$ specificity in discriminating PTB from HCs.

\section{Metabolomics}

Metabolomics is a field newly developed after genomics and proteomics, and it is an important part of systems biology. Genomics and proteomics explore the processes of life at the gene and protein levels, respectively. In fact, many life activities in cells occur at the level of metabolites, such as cell signaling, energy transfer, and cell-to-cell communication (Griffiths and Wang, 2009). Since the metabolome is the final downstream product of the genome, transcriptome, and proteome, any interference at these levels will change the metabolome. In 2017, Preez et al. (2017) reviewed and summarized abundant biomarkers related to $\mathrm{TB}$ diseases that have been identified in culture (Phillips et al., 2007; Syhre and Chambers, 2008; Olivier and Loots du, 2012; Lau et al., 2015), human sputum (Schoeman et al., 2012; du Preez and Loots, 2013), animal or human blood and tissue (Shin et al., 2011; Somashekar et al., 2012; Weiner et al., 2012;
Che et al., 2013; Zhou et al., 2013; Frediani et al., 2014; Feng et al., 2015), human urine (Banday et al., 2011; Das et al., 2015), and human breath (Phillips et al., 2007; Syhre et al., 2009; Phillips et al., 2010; Kolk et al., 2012) using a metabolomics research approach (Preez et al., 2017). However, most of the signatures identified in these studies were obtained by comparing patients with $\mathrm{TB}$ and $\mathrm{HCs}$ or other diseases, and only one study was performed among patients with $\mathrm{TB}$, individuals with LTBI, and HCs. In this study, Weiner et al. (2012) explored the metabolites in serum collected from three groups of individuals, and their results showed that compared to individuals with LTBI, patients with aTB showed increased indoleamine 2,3 dioxygenase 1 activity, decreased phospholipase activity, increased adenosine metabolite abundance, and increased levels of fibrotic disease indicators. Furthermore, they also found that the abundance of inosine was significantly lower in individuals with LTBI than in patients with TB and HCs (Weiner et al., 2012). More recently, Dutta et al. (2020) analyzed the plasma metabolite profiles of 16 aTB children and 32 household contacts in India using liquid chromatography-mass spectrometry and identified three metabolites ( $\mathrm{N}$-acetylneuraminate, quinolinate, and pyridoxate) that could correctly discriminate TB status at distinct times during treatment, with AUCs of 0.66, 0.87, and 0.86, respectively. Although the above studies have used metabolomics techniques to identify abundant biomarkers for distinguishing aTB from individuals with LTBI, they have not linked metabolomics with transcriptomics and proteomics. Integrating metabolomics data with transcriptomics and proteomics data to comprehensively analyze and identify novel biomarkers is a direction for future omics technology development. Saiboonjan et al. (2021) investigated the transcriptomics, proteomics, and metabolomics profiles of three strains of $M$. tuberculosis (including drugsusceptible Beijing strain, multidrug-resistant Beijing strain, and H37Rv strain) cultured under stress conditions to mimic the environment of the host granuloma. They found that NarJ (respiratory nitrate reductase delta chain) was significantly upregulated at the protein and mRNA levels in all three M. tuberculosis strains and that NarJ plays an important role in nitrate metabolism during the adaptation of M. tuberculosis to stressful and intracellular environments and subsequent establishment of LTBI (Saiboonjan et al., 2021).

\section{Microbiota}

Hundreds of millions of microorganisms have coexisted with humans in the respiratory tract and gastrointestinal tract for thousands of years. However, research on them has been recently increasing. A growing number of studies have suggested that the microbiota plays an essential role in maintaining normal health, developing the immune system, and providing protection against pathogens (Khan et al., 2016; Dumas et al., 2018; Gupta et al., 2018; Liu et al., 2021). However, the impact of microbiota on host defense against $M$. tuberculosis infection is poorly understood. A recent review published in PLOS Pathogens summarized 14 microbiome studies performed on animal models of TB and patients with TB (Mori et al., 2021). Among these studies, nine focused on the relationship between microbiota in the intestinal tract and M. tuberculosis, including five studies on patients 
with $\mathrm{TB}$, three studies on mouse models, and one study on rhesus macaques. Compared with the number of studies on the intestinal tract, only six studies have been performed to explore the correlations between microbiota in the respiratory tract and M. tuberculosis, including five studies on patients with TB and one study on rhesus macaques. These studies investigated the impact of $M$. tuberculosis infection on the host microbiome, and all of them found that $M$. tuberculosis infection changed the composition of microbiota, with only four studies reporting the impact of microbiota changes caused by $M$. tuberculosis infection on the immune system. It is important to note that one study compared the changes in the composition of microbiota and its effects on the immune system among patients with TB $(n=25)$, patients with LTBI $(n=32)$, and healthy individuals $(n=23)$ (Huang et al., 2019). The results suggested that dysbiosis with a higher abundance of Bacteroidetes and a low ratio of Firmicutes to Bacteroidetes was related to systemic proinflammation in patients with aTB, while the abundance of Coriobacteriaceae was positively related to the level of IFN- $\gamma$ and $\mathrm{CD} 4^{+} \mathrm{T}$ cells in LTBI.

It is becoming increasingly recognized that the composition of the respiratory and gastrointestinal microbiota may affect the systemic immune responses of the host, and that microbiomeimmune interactions may affect the susceptibility, manifestation, and progression of M. tuberculosis infection (Wipperman et al., 2021). However, the results of most studies are inconsistent and contradictory. This may be due to differences in species, heterogeneity of microbiota between individuals, sample size, detection methods, and experimental design, among others. The current data cannot determine whether microbiota can be used to distinguish between LTBI and aTB, and more high-quality studies with larger sample sizes are urgently needed to clarify this.

\section{CONCLUSION}

Tuberculosis is a global infectious disease that threatens human health, and LTBI is the biggest obstacle to achieving the goal of ending the global TB epidemic shared by the UN Sustainable Development Goals and WHO's End TB Strategy. As an ancient test that has been used to diagnose TB for more than 100 years, the TST has made great contributions to the control of TB. However, the TST has several challenges, such as the need for return visits, low specificity and sensitivity, false positives with BCG vaccination, cross-reactivity with NTMs, and false positives in immunosuppression and deficiency. To overcome these shortcomings of the TST, several new detection methods have been developed, such as the Diaskintest, C-Tb skin test, EC-Test, and T-SPOT.TB, QFT-GIT, QFT-Plus, LIAISON QFTPlus, and LIOFeron TB/LTBI. The application of RD antigens (ESAT-6, CFP-10, TB7.7, and Ala-DH) prevents these novel methods from cross-reacting with BCG inoculation and most NTM infections, with the additional advantages of having higher specificity and sensitivity.

However, these methods cannot distinguish between LTBI and aTB. To investigate the reasons behind this, we believe that the abovementioned methods (1) were only designed based on $\mathrm{RD}$ antigens rather than LTBI-RD-associated antigens (Rv1736c,
Rv1737c, Rv2031c, Rv2626c, Rv2653c-Rv2660c, Rv1511, Rv1978, Rv1980c, Rv1981c, Rv3872, Rv3873, Rv3878, Rv3879c, Rv3425, and Rv3429), without considering the difference in profiles of antigen expression between latent and active infection of $M$. tuberculosis; (2) only detect the number of IFN- $\gamma$-producing $\mathrm{T}$ cells and serum concentrations of IFN- $\gamma$ produced by $\mathrm{CD} 4^{+}$ and/or $\mathrm{CD}^{+} \mathrm{T}$ cells, but not of other biomarkers, such as antigen-specific antibodies, IL-2, IL-10, IP-10, and VEGF, nor their combinations; and (3) did not use the latest models and algorithms to improve their diagnosis performance for distinguishing between LTBI and aTB.

Thus, areas for further investigation and development should include (1) understanding the differential expression of various antigens in latent and active infection of M. tuberculosis based on omics technologies and studies with larger sample sizes, (2) focusing on multiple cytokines and/or antibodies derived from hosts that have been identified by previous studies, (3) improving the sensitivity and specificity of LTBI differential diagnosis using new models, algorithms, and IS, and (4) exploring the differences in microbiota between patients with LTBI and aTB to find new evidence for improving the diagnostic accuracy of LTBI and aTB.

\section{AUTHOR CONTRIBUTIONS}

XW and WG did the conceptualization and wrote-reviewed and edited. WG did the data curation, formal analysis, funding acquisition, methodology, software, and writing-original draft. Both authors contributed to the article and approved the submitted version.

\section{FUNDING}

This study was funded by the Beijing Municipal Science \& Technology Commission (Grant Nos. 7212103 and Z181100001718005).

\section{ACKNOWLEDGMENTS}

We would like to thank Zimeng Yuan from The 8th Medical Center of PLA General Hospital for editing the article for language. We would also like to thank Editage for English language editing. Some elements of figures were obtained from BIORENDER (https://app.biorender.com/).

\section{SUPPLEMENTARY MATERIAL}

The Supplementary Material for this article can be found online at: https://www.frontiersin.org/articles/10.3389/fmicb.2021. 745592/full\#supplementary-material

Supplementary Figure 1 | Twenty-six cytokines were summarized from 34 included publications by Meier, N. R. et al. in a systematic review (Meier et al., 2018). The number of publications related each cytokine was showed as histogram. 


\section{REFERENCES}

Abedi, S., Moosazadeh, M., Afshari, M., Charati, J. Y., and Nezammahalleh, A. (2019). Determinant factors for mortality during treatment among tuberculosis patients: cox proportional hazards model. Indian J. Tuberc. 66, 39-43. doi: 10.1016/j.ijtb.2017.05.001

Acharya, M. P., Pradeep, S. P., Murthy, V. S., Chikkannaiah, P., Kambar, V., Narayanashetty, S., et al. (2021). CD38 +CD27 -TNF- $\alpha+$ on Mtb-specific CD4 $+\mathrm{T}$ is a robust biomarker for tuberculosis diagnosis. Clin. Infect. Dis. 110, 204-209. doi: 10.1093/cid/ciab144

Achkar, J. M., Chan, J., and Casadevall, A. (2015). B cells and antibodies in the defense against Mycobacterium tuberculosis infection. Immunol. Rev. 264, 167-181. doi: 10.1111/imr.12276

Aggerbeck, H., Giemza, R., Joshi, P., Tingskov, P. N., Hoff, S. T., Boyle, J., et al. (2013). Randomised clinical trial investigating the specificity of a novel skin test (C-Tb) for diagnosis of M. tuberculosis infection. PLoS One 8:e64215. doi: 10.1371/journal.pone.0064215

Aggerbeck, H., Ruhwald, M., Hoff, S. T., Borregaard, B., Hellstrom, E., Malahleha, M., et al. (2018). C-Tb skin test to diagnose Mycobacterium tuberculosis infection in children and HIV-infected adults: a phase 3 trial. PLoS One 13:e0204554. doi: 10.1371/journal.pone.0204554

Agren, D., Stehr, M., Berthold, C. L., Kapoor, S., Oehlmann, W., Singh, M., et al. (2008). Three-dimensional structures of apo- and holo-Lalanine dehydrogenase from Mycobacterium tuberculosis reveal conformational changes upon coenzyme binding. J. Mol. Biol. 377, 1161-1173. doi: 10.1016/j. jmb.2008.01.091

Al-Khodari, N. Y., Al-Attiyah, R., and Mustafa, A. S. (2011). Identification, diagnostic potential, and natural expression of immunodominant seroreactive peptides encoded by five Mycobacterium tuberculosis-specific genomic regions. Clin. Vaccine Immunol. 18, 477-482. doi: 10.1128/cvi.00405-10

Allen, M., Bailey, C., Cahatol, I., Dodge, L., Yim, J., Kassissa, C., et al. (2015). Mechanisms of control of Mycobacterium tuberculosis by NK cells: role of glutathione. Front. Immunol. 6:508. doi: 10.3389/fimmu.20 15.00508

Alsleben, N., Ruhwald, M., Rüssmann, H., Marx, F. M., Wahn, U., and Magdorf, K. (2012). Interferon-gamma inducible protein 10 as a biomarker for active tuberculosis and latent tuberculosis infection in children: a case-control study. Scand. J. Infect. Dis. 44, 256-262. doi: 10.3109/00365548.2011.632644

Altawallbeh, G., Gabrielson, D., Peters, J. M., and Killeen, A. A. (2021). Performance of an advanced interferon-gamma release assay for Mycobacterium tuberculosis detection. J. Appl. Lab. Med. 6, 1287-1292. doi: $10.1093 / \mathrm{jalm} / \mathrm{jfab} 012$

Amiano, N. O., Morelli, M. P., Pellegrini, J. M., Tateosian, N. L., Rolandelli, A., Seery, V., et al. (2020). IFN-gamma and IgG responses to Mycobacterium tuberculosis latency antigen Rv2626c differentiate remote from recent tuberculosis infection. Sci. Rep. 10:7472. doi: 10.1038/s41598-020-64428-z

Andersen, P., Munk, M. E., Pollock, J. M., and Doherty, T. M. (2000). Specific immune-based diagnosis of tuberculosis. Lancet 356, 1099-1104. doi: 10.1016/ s0140-6736(00)02742-2

Araujo, L. S., da Silva, N. B. M., da Silva, R. J., Leung, J. A. M., Mello, F. C. Q., and Saad, M. H. F. (2015). Profile of interferon-gamma response to latencyassociated and novel in vivo expressed antigens in a cohort of subjects recently exposed to Mycobacterium tuberculosis. Tuberculosis (Edinb) 95, 751-757. doi: 10.1016/j.tube.2015.08.002

Arroyo, L., Rojas, M., Franken, K. L., Ottenhoff, T. H., and Barrera, L. F. (2016). Multifunctional T cell response to DosR and Rpf antigens is associated with protection in long-term Mycobacterium tuberculosis-infected individuals in Colombia. Clin Vaccine Immunol 23, 813-824. doi: 10.1128/CVI.002 17-16

Ashraf, S., Saqib, M. A., Sharif, M. Z., Khatak, A. A., Khan, S. N., Malik, S. A., et al. (2014). Evaluation of diagnostic potential of Rv3803c and Rv2626c recombinant antigens in TB endemic country Pakistan. J. Immunoassay Immunochem. 35, 120-129. doi: 10.1080/15321819.2013.824897

Aspatwar, A., Gong, W., Wang, S., Wu, X., and Parkkila, S. (2021). Tuberculosis vaccine BCG: the magical effect of the old vaccine in the fight against the COVID-19 pandemic. Int. Rev. Immunol. 1-14. doi: 10.1080/08830185.2021. 1922685 [Epub ahead of print].
ATS (2000). Targeted tuberculin testing and treatment of latent tuberculosis infection. This official statement of the American Thoracic Society was adopted by the ATS Board of Directors, July 1999. This is a Joint Statement of the American Thoracic Society (ATS) and the Centers for Disease Control and Prevention (CDC). This statement was endorsed by the Council of the Infectious Diseases Society of America. (IDSA), September 1999, and the sections of this statement. Am. J. Respir. Crit. Care Med. 161(4 Pt 2), S221-S247. doi: 10.1164/ajrccm.161.supplement_3.ats600

Bai, X. (2015). Preparation of Four Tuberculosis Latent Proteins and the Evaluation of Their Immunological Characteristic. Doctor. Beijing: Medical School of Chinese PLA.

Banday, K. M., Pasikanti, K. K., Chan, E. C., Singla, R., Rao, K. V., Chauhan, V. S., et al. (2011). Use of urine volatile organic compounds to discriminate tuberculosis patients from healthy subjects. Anal. Chem. 83, 5526-5534. doi: $10.1021 / \mathrm{ac} 200265 \mathrm{~g}$

Banerjee, U., Baloni, P., Singh, A., and Chandra, N. (2021). Immune subtyping in latent tuberculosis. Front. Immunol. 12:595746. doi: 10.3389/fimmu.2021. 595746

Bayaa, R., Ndiaye, M. D. B., Chedid, C., Kokhreidze, E., Tukvadze, N., Banu, S., et al. (2021). Multi-country evaluation of RISK6, a 6-gene blood transcriptomic signature, for tuberculosis diagnosis and treatment monitoring. Sci. Rep. 11:13646. doi: 10.1038/s41598-021-93059-1

Behr, M. A., Edelstein, P. H., and Ramakrishnan, L. (2018). Revisiting the timetable of tuberculosis. BMJ 362:k2738. doi: 10.1136/bmj.k2738

Behr, M. A., Edelstein, P. H., and Ramakrishnan, L. (2019). Is Mycobacterium tuberculosis infection life long? BMJ 367:15770. doi: 10.1136/bmj.15770

Behr, M. A., Kaufmann, E., Duffin, J., Edelstein, P. H., and Ramakrishnan, L. (2021). Latent tuberculosis: two centuries of confusion. Am. J. Respir. Crit. Care Med. 204, 142-148. doi: 10.1164/rccm.202011-4239PP

Belay, M., Legesse, M., Mihret, A., Bekele, Y., Ottenhoff, T. H. M., Franken, K. L. M. C., et al. (2015). Pro- and anti-inflammatory cytokines against Rv2031 Are elevated during latent tuberculosis: a study in cohorts of tuberculosis patients, household contacts and community controls in an endemic setting. PLoS One 10:e0124134. doi: 10.1371/journal.pone.0124134

Berry, M. P., Graham, C. M., McNab, F. W., Xu, Z., Bloch, S. A., Oni, T., et al. (2010). An interferon-inducible neutrophil-driven blood transcriptional signature in human tuberculosis. Nature 466, 973-977. doi: 10.1038/nature0 9247

Betts, J. C. (2002). Transcriptomics and proteomics: tools for the identification of novel drug targets and vaccine candidates for tuberculosis. IUBMB Life 53, 239-242. doi: 10.1080/15216540212651

Bruns, H., Meinken, C., Schauenberg, P., Härter, G., Kern, P., Modlin, R. L., et al. (2009). Anti-TNF immunotherapy reduces CD8+ T cell-mediated antimicrobial activity against Mycobacterium tuberculosis in humans. J. Clin. Invest. 119, 1167-1177. doi: 10.1172/jci38482

Bui, H. H., Sidney, J., Dinh, K., Southwood, S., Newman, M. J., and Sette, A. (2006). Predicting population coverage of T-cell epitope-based diagnostics and vaccines. BMC Bioinformatics 7:153. doi: 10.1186/1471-2105-7-153

Cao, S. H., Chen, Y. Q., Sun, Y., Liu, Y., Zheng, S. H., Zhang, Z. G., et al. (2018). Screening of serum biomarkers for distinguishing between latent and active tuberculosis using proteome microarray. Biomed. Environ. Sci. 31, 515-526. doi: 10.3967/bes2018.069

Cao, X. J., Li, Y. P., Wang, J. Y., Zhou, J., and Guo, X. G. (2021). MPT64 assays for the rapid detection of Mycobacterium tuberculosis. BMC Infect Dis 21:336. doi: 10.1186/s12879-021-06022-w

Chai, Q., Lu, Z., and Liu, C. H. (2020). Host defense mechanisms against Mycobacterium tuberculosis. Cell Mol. Life Sci. 77, 1859-1878. doi: 10.1007/ s00018-019-03353-5

Chaw, L., Chien, L. C., Wong, J., Takahashi, K., Koh, D., and Lin, R. T. (2020). Global trends and gaps in research related to latent tuberculosis infection. BMC Public Health 20:352. doi: 10.1186/s12889-020-8419-0

Che, N., Cheng, J., Li, H., Zhang, Z., Zhang, X., Ding, Z., et al. (2013). Decreased serum 5-oxoproline in TB patients is associated with pathological damage of the lung. Clin. Chim. Acta 423, 5-9. doi: 10.1016/j.cca.2013.04.010

Chee, C. B. E., Reves, R., Zhang, Y., and Belknap, R. (2018). Latent tuberculosis infection: opportunities and challenges. Respirology 23, 893-900. doi: 10.1111/ resp.13346 
Chegou, N. N., Essone, P. N., Loxton, A. G., Stanley, K., Black, G. F., van der Spuy, G. D., et al. (2012). Potential of host markers produced by infection phase-dependent antigen-stimulated cells for the diagnosis of tuberculosis in a highly endemic area. PLoS One 7:e38501. doi: 10.1371/journal.pone.003 8501

Chen, F., Zhai, M. X., Zhu, Y. H., Qi, Y. M., Zhai, W. J., and Gao, Y. F. (2012). In vitro and in vivo identification of a novel cytotoxic $\mathrm{T}$ lymphocyte epitope from Rv3425 of Mycobacterium tuberculosis. Microbiol. Immunol. 56, 548-553. doi: 10.1111/j.1348-0421.2012.00470.x

Chen, J., Su, X., Zhang, Y., Wang, S., Shao, L., Wu, J., et al. (2009). Novel recombinant $\mathrm{RD} 2-$ and $\mathrm{RD} 11$-encoded Mycobacterium tuberculosis antigens are potential candidates for diagnosis of tuberculosis infections in BCGvaccinated individuals. Microbes Infect. 11, 876-885. doi: 10.1016/j.micinf.2009. 05.008

Chinese Antituberculosis Association, Schools and Children Branch of the Chinese Antituberculosis Association, and Editorial Board of Chinese Journal of Antituberculosis (2020). [Expert consensus of clinical application of the recombinant Mycobacterium tuberculosis fusion protein (EC)]. Chin. J. Antituberculosis 42, 761-768. doi: 10.3969/i.issn.1000-6621.2020.0 8.001

Cole, S. T., Brosch, R., Parkhill, J., Garnier, T., Churcher, C., Harris, D., et al. (1998). Deciphering the biology of Mycobacterium tuberculosis from the complete genome sequence. Nature 393, 537-544. doi: 10.1038/31159

Commandeur, S., Lin, M. Y., van Meijgaarden, K. E., Friggen, A. H., Franken, K. L., Drijfhout, J. W., et al. (2011). Double- and monofunctional CD4 ${ }^{+}$and CD8 ${ }^{+}$ T-cell responses to Mycobacterium tuberculosis DosR antigens and peptides in long-term latently infected individuals. Eur. J. Immunol. 41, 2925-2936. doi: 10.1002/eji.201141602

Coppola, M., van den Eeden, S. J., Wilson, L., Franken, K. L., Ottenhoff, T. H., and Geluk, A. (2015). Synthetic long peptide derived from Mycobacterium tuberculosis latency antigen Rv1733c protects against tuberculosis. Clin. Vaccine Immunol. 22, 1060-1069. doi: 10.1128/CVI.00271-15

Cui, X., Gao, L., and Cao, B. (2020). Management of latent tuberculosis infection in China: exploring solutions suitable for high-burden countries. Int. J. Infect. Dis. 92S, S37-S40. doi: 10.1016/j.ijid.2020.02.034

da Silva, R. J., da Silva Correa, R., Sardella, I. G., de Paulo Mulinari, A. C., Mafort, T. T., Santos, A. P., et al. (2019). IgA and IgG antibody detection of mycobacterial antigens in pleural fluid and serum from pleural tuberculous patients. BMC Immunol. 20:36. doi: 10.1186/s12865-019-0315-y

Das, M. K., Bishwal, S. C., Das, A., Dabral, D., Badireddy, V. K., Pandit, B., et al. (2015). Deregulated tyrosine-phenylalanine metabolism in pulmonary tuberculosis patients. J. Proteome Res. 14, 1947-1956. doi: 10.1021/acs. jproteome.5b00016

De Maertelaere, E., Vandendriessche, S., Verhasselt, B., Coorevits, L., Andre, E., Padalko, E., et al. (2020). Evaluation of QuantiFERON-TB gold plus on liaison XL in a low-tuberculosis-incidence setting. J. Clin. Microbiol. 58, e00159-e20. doi: 10.1128/JCM.00159-20

Della Bella, C., Spinicci, M., Alnwaisri, H. F. M., Bartalesi, F., Tapinassi, S., Mencarini, J., et al. (2020). LIOFeron(R)TB/LTBI: a novel and reliable test for LTBI and tuberculosis. Int. J. Infect. Dis. 91, 177-181. doi: 10.1016/j.ijid.2019.12. 012

Dong, Y., Demaria, S., Sun, X., Santori, F. R., Jesdale, B. M., De Groot, A. S., et al. (2004). HLA-A2-restricted CD8+-cytotoxic-T-cell responses to novel epitopes in Mycobacterium tuberculosis superoxide dismutase, alanine dehydrogenase, and glutamine synthetase. Infect. Immun. 72, 2412-2415. doi: 10.1128/iai.72.4. 2412-2415.2004

du Preez, I., and Loots, D. T. (2013). New sputum metabolite markers implicating adaptations of the host to Mycobacterium tuberculosis, and vice versa. Tuberculosis (Edinb) 93, 330-337. doi: 10.1016/j.tube.2013.02.008

Dubois Cauwelaert, N., Baldwin, S. L., Orr, M. T., Desbien, A. L., Gage, E., Hofmeyer, K. A., et al. (2016). Antigen presentation by B cells guides programing of memory CD4(+) T-cell responses to a TLR4-agonist containing vaccine in mice. Eur. J. Immunol. 46, 2719-2729. doi: 10.1002/eji.201646399

Dumas, A., Corral, D., Colom, A., Levillain, F., Peixoto, A., Hudrisier, D., et al. (2018). The host microbiota contributes to early protection against lung colonization by Mycobacterium tuberculosis. Front. Immunol. 9:2656. doi: 10. 3389/fimmu.2018.02656
Dutta, N. K., Tornheim, J. A., Fukutani, K. F., Paradkar, M., Tiburcio, R. T., Kinikar, A., et al. (2020). Integration of metabolomics and transcriptomics reveals novel biomarkers in the blood for tuberculosis diagnosis in children. Sci. Rep. 10:19527. doi: 10.1038/s41598-020-75513-8

Emery, J. C., Richards, A. S., Dale, K. D., McQuaid, C. F., White, R. G., Denholm, J. T., et al. (2021). Self-clearance of Mycobacterium tuberculosis infection: implications for lifetime risk and population at-risk of tuberculosis disease. Proc. Biol. Sci. 288:20201635. doi: 10.1098/rspb.2020.1635

Feng, S., Du, Y. Q., Zhang, L., Zhang, L., Feng, R. R., and Liu, S. Y. (2015). Analysis of serum metabolic profile by ultra-performance liquid chromatographymass spectrometry for biomarkers discovery: application in a pilot study to discriminate patients with tuberculosis. Chin. Med. J. (Engl) 128, 159-168. doi: 10.4103/0366-6999.149188

Feng, X., Xiu, B., Chen, K., Yang, X., Zhang, H., Yue, J., et al. (2013). Enhanced serodiagnostic utility of novel Mycobacterium tuberculosis polyproteins. J. Infect. 66, 366-375. doi: 10.1016/j.jinf.2012.10.029

Floyd, K., Glaziou, P., Zumla, A., and Raviglione, M. (2018). The global tuberculosis epidemic and progress in care, prevention, and research: an overview in year 3 of the End TB era. Lancet Respir. Med. 6, 299-314. doi: 10.1016/S2213-2600(18) 30057-2

Frediani, J. K., Jones, D. P., Tukvadze, N., Uppal, K., Sanikidze, E., Kipiani, M., et al. (2014). Plasma metabolomics in human pulmonary tuberculosis disease: a pilot study. PLoS One 9:e108854. doi: 10.1371/journal.pone.0108854

Geluk, A., Lin, M. Y., van Meijgaarden, K. E., Leyten, E. M., Franken, K. L., Ottenhoff, T. H., et al. (2007). T-cell recognition of the HspX protein of Mycobacterium tuberculosis correlates with latent $M$. tuberculosis infection but not with M. bovis BCG vaccination. Infect. Immun. 75, 2914-2921. doi: 10.1128/ iai.01990-06

Godoy, P. (2021). Guidelines on controlling latent tuberculosis infection to support tuberculosis elimination. Rev. Esp. Sanid. Penit. 23, 28-36. doi: 10.18176/resp. 00028

Gong, W., Liang, Y., Mi, J., Jia, Z., Xue, Y., Wang, J., et al. (2021). Peptidesbased vaccine MP3RT induced protective immunity against Mycobacterium Tuberculosis infection in a humanized mouse model. Front. Immunol. 12:666290. doi: 10.3389/fimmu.2021.666290

Gong, W., Liang, Y., and Wu, X. (2018). The current status, challenges, and future developments of new tuberculosis vaccines. Hum. Vaccin Immunother. 14, 1697-1716. doi: 10.1080/21645515.2018.1458806

Gong, W., and Wu, X. (2020). Is the tuberculosis vaccine BCG an alternative weapon for developing countries to defeat COVID-19? Indian J. Tuberc. 68, 401-404.

Gong, W. P., Liang, Y., Ling, Y. B., Zhang, J. X., Yang, Y. R., Wang, L., et al. (2020). Effects of Mycobacterium vaccae vaccine in a mouse model of tuberculosis: protective action and differentially expressed genes. Mil. Med. Res. 7:25. doi: 10.1186/s40779-020-00258-4

Gordon, S. V., Eiglmeier, K., Garnier, T., Brosch, R., Parkhill, J., Barrell, B., et al. (2001). Genomics of Mycobacterium bovis. Tuberculosis (Edinb) 81, 157-163. doi: 10.1054/tube.2000.0269

Griffiths, W. J., and Wang, Y. (2009). Mass spectrometry: from proteomics to metabolomics and lipidomics. Chem. Soc. Rev. 38, 1882-1896. doi: 10.1039/ b618553n

Gupta, N., Kumar, R., and Agrawal, B. (2018). New players in immunity to tuberculosis: the host microbiome, Lung Epithelium, and Innate Immune Cells. Front. Immunol. 9:709. doi: 10.3389/fimmu.2018.00709

Hamada, Y., Cirillo, D. M., Matteelli, A., Penn-Nicholson, A., Rangaka, M. X., and Ruhwald, M. (2021). Tests for tuberculosis infection: landscape analysis. Eur. Respir. J. 2100167. doi: 10.1183/13993003.00167-2021

Hanif, S. N., Al-Attiyah, R., and Mustafa, A. S. (2011). Cellular immune responses in mice induced by $M$. tuberculosis PE35-DNA vaccine construct. Scand. J. Immunol. 74, 554-560. doi: 10.1111/j.1365-3083.2011.02 604.x

Hauck, F. R., Neese, B. H., Panchal, A. S., and El-Amin, W. (2009). Identification and management of latent tuberculosis infection. Am. Fam. Physician 79, 879-886.

He, H., Yang, H., and Deng, Y. (2015). Mycobacterium tuberculosis dormancyassociated antigen of Rv2660c induces stronger immune response in latent Mycobacterium tuberculosis infection than that in active tuberculosis in a 
Chinese population. Eur. J. Clin. Microbiol. Infect. Dis. 34, 1103-1109. doi: 10.1007/s10096-015-2335-8

Hinks, T. S., Dosanjh, D. P., Innes, J. A., Pasvol, G., Hackforth, S., Varia, H., et al. (2009). Frequencies of region of difference 1 antigen-specific but not purified protein derivative-specific gamma interferon-secreting T cells correlate with the presence of tuberculosis disease but do not distinguish recent from remote latent infections. Infect. Immun. 77, 5486-5495. doi: 10.1128/iai.014 36-08

Hoff, S. T., Peter, J. G., Theron, G., Pascoe, M., Tingskov, P. N., Aggerbeck, H., et al. (2016). Sensitivity of C-Tb: a novel RD-1-specific skin test for the diagnosis of tuberculosis infection. Eur. Respir. J. 47, 919-928. doi: 10.1183/13993003. 01464-2015

Honaker, R. W., Stewart, A., Schittone, S., Izzo, A., Klein, M. R., and Voskuil, M. I. (2008). Mycobacterium bovis BCG vaccine strains lack narK2 and narX induction and exhibit altered phenotypes during dormancy. Infect. Immun. 76, 2587-2593. doi: 10.1128/IAI.01235-07

Hong, J. Y., Park, S. Y., Kim, A., Cho, S. N., and Hur, Y. G. (2019). Comparison of QFT-Plus and QFT-GIT tests for diagnosis of M. tuberculosis infection in immunocompetent Korean subjects. J. Thorac. Dis. 11, 5210-5217. doi: 10. 21037/jtd.2019.12.11

Horvati, K., Bosze, S., Gideon, H. P., Bacsa, B., Szabo, T. G., Goliath, R., et al. (2016). Population tailored modification of tuberculosis specific interferon-gamma release assay. J. Infect. 72, 179-188. doi: 10.1016/j.jinf.2015.10.012

Houben, R. M., and Dodd, P. J. (2016). The global burden of latent tuberculosis infection: a Re-estimation using mathematical modelling. PLoS Med 13:e1002152. doi: 10.1371/journal.pmed.1002152

Huang, S. F., Yang, Y. Y., Chou, K. T., Fung, C. P., Wang, F. D., and Su, W. J. (2019). Systemic proinflammation after Mycobacterium tuberculosis infection was correlated to the gut microbiome in HIV-uninfected humans. Eur. J. Clin. Invest. 49:e13068. doi: 10.1111/eci.13068

Jacobsen, M., Repsilber, D., Gutschmidt, A., Neher, A., Feldmann, K., Mollenkopf, H. J., et al. (2007). Candidate biomarkers for discrimination between infection and disease caused by Mycobacterium tuberculosis. J. Mol. Med. (Berl) 85, 613-621. doi: 10.1007/s00109-007-0157-6

Jasenosky, L. D., Scriba, T. J., Hanekom, W. A., and Goldfeld, A. E. (2015). T cells and adaptive immunity to Mycobacterium tuberculosis in humans. Immunol. Rev. 264, 74-87. doi: 10.1111/imr.12274

Ji, P., Fan, X., Wu, K., and Lu, S. (2015). [Research progress on the antigens associated with latent infection of Mycobacterium tuberculosis]. Chin. J.Microbiol. Immunol. 35, 59-64. doi: 10.3760/cma.j.issn.0254-5101.2015.01. 013

Jia, Z., Gong, W., Liang, Y., Wu, X., and Zhao, W. (2021). Prediction and analyses of HLA-II restricted Mycobacterium tuberculosis CD4(+) T cell epitopes in the Chinese population. Biotechnol. Appl. Biochem. 2021, 1-13. doi: 10.1002/bab. 2171

Jiang, Y., Wei, J., Liu, H., Li, G., Guo, Q., Qiu, Y., et al. (2016). Polymorphisms in the PE35 and PPE68 antigens in Mycobacterium tuberculosis strains may affect strain virulence and reflect ongoing immune evasion. Mol. Med. Rep. 13, 947-954. doi: 10.3892/mmr.2015.4589

Jungblut, P. R., Schaible, U. E., Mollenkopf, H. J., Zimny-Arndt, U., Raupach, B., Mattow, J., et al. (1999). Comparative proteome analysis of Mycobacterium tuberculosis and Mycobacterium bovis BCG strains: towards functional genomics of microbial pathogens. Mol. Microbiol. 33, 1103-1117. doi: 10.1046/ j.1365-2958.1999.01549.x

Kadkhoda, K., Schwichtenberg, G., Dee, M., and Horejsei, R. (2020). Operational usability evaluation of the LIAISON(R) QuantiFERON(R)-TB gold plus solution in a high volume laboratory setting. Clin. Lab. 66:11. doi: 10.7754/Clin. Lab.2020.200338

Kanai, K., Kondo, E., and Yasuda, T. (1979). Ultrastructural changes in the alveolar epithelium in response to mycobacterial infection. Jpn. J. Med. Sci. Biol. 32, 315-325. doi: 10.7883/yoken1952.32.315

Kasempimolporn, S., Areekul, P., Thaveekarn, W., Sutthisri, R., Boonchang, S., Sawangvaree, A., et al. (2019). Application of transdermal patches with new skin test reagents for detection of latent tuberculosis. J. Med. Microbiol. 68, 1314-1319. doi: $10.1099 / \mathrm{jmm} .0 .001037$

Khan, N., Vidyarthi, A., Nadeem, S., Negi, S., Nair, G., and Agrewala, J. N. (2016). Alteration in the gut microbiota provokes susceptibility to tuberculosis. Front. Immunol. 7:529. doi: 10.3389/fimmu.2016.00529
Kolk, A. H., van Berkel, J. J., Claassens, M. M., Walters, E., Kuijper, S., Dallinga, J. W., et al. (2012). Breath analysis as a potential diagnostic tool for tuberculosis. Int. J. Tuberc. Lung Dis. 16, 777-782. doi: 10.5588/ijtld.11.0576

Korma, W., Mihret, A., Chang, Y., Tarekegn, A., Tegegn, M., Tuha, A., et al. (2020). Antigen-specific cytokine and chemokine gene expression for diagnosing latent and active tuberculosis. Diagnostics (Basel) 10:716. doi: 10. 3390/diagnostics10090716

Kundu, M., and Basu, J. (2021). Applications of transcriptomics and proteomics for understanding dormancy and resuscitation in Mycobacterium tuberculosis. Front. Microbiol. 12:642487. doi: 10.3389/fmicb.2021.642487

Laennec, R. (1826). Traite de l'Auscultation Mediate et des Maladies des Poumons et $d u$ Coeur. Paris: Chaude.

Lalvani, A., Pathan, A. A., McShane, H., Wilkinson, R. J., Latif, M., Conlon, C. P., et al. (2001). Rapid detection of Mycobacterium tuberculosis infection by enumeration of antigen-specific T cells. Am. J. Respir. Crit. Care Med. 163, 824-828. doi: 10.1164/ajrccm.163.4.2009100

Latorre, I., Fernández-Sanmartín, M. A., Muriel-Moreno, B., Villar-Hernández, R., Vila, S., Souza-Galvão, M. L., et al. (2018). Study of CD27 and CCR4 Markers on specific CD4(+) T-cells as immune tools for active and latent tuberculosis management. Front. Immunol. 9:3094. doi: 10.3389/fimmu.2018.03094

Lau, S. K., Lam, C. W., Curreem, S. O., Lee, K. C., Lau, C. C., Chow, W. N., et al. (2015). Identification of specific metabolites in culture supernatant of Mycobacterium tuberculosis using metabolomics: exploration of potential biomarkers. Emerg. Microbes Infect. 4:e6. doi: 10.1038/emi.2015.6

Lewinsohn, D. M., Leonard, M. K., LoBue, P. A., Cohn, D. L., Daley, C. L., Desmond, E., et al. (2017). Official American thoracic society/infectious diseases society of America/Centers for disease control and prevention clinical practice guidelines: diagnosis of tuberculosis in adults and children. Clin. Infect. Dis. 64, e1-e33. doi: 10.1093/cid/ciw694

Li, F., Xu, M., Qin, C., Xia, L., Xiong, Y., Xi, X., et al. (2016a). Recombinant fusion ESAT6-CFP10 immunogen as a skin test reagent for tuberculosis diagnosis: an open-label, randomized, two-centre phase 2a clinical trial. Clin. Microbiol. Infect. 22, 889.e9-889.e16. doi: 10.1016/j.cmi.2016.07.015

Li, F., Xu, M., Zhou, L., Xiong, Y., Xia, L., Fan, X., et al. (2016b). Safety of Recombinant fusion protein ESAT6-CFP10 as a skin test reagent for tuberculosis diagnosis: an open-label, randomized, single-center phase I clinical trial. Clin. Vaccine Immunol. 23, 767-773. doi: 10.1128/CVI.00154-16

Li, G., Yang, F., He, X., Liu, Z., Pi, J., Zhu, Y., et al. (2020). Anti-tuberculosis (TB) chemotherapy dynamically rescues Th1 and CD8+ T effector levels in Han Chinese pulmonary TB patients. Microbes Infect. 22, 119-126. doi: 10.1016/j. micinf.2019.10.001

Liang, Y., Gong, W., Wang, X., Zhang, J., Ling, Y., Song, J., et al. (2021). Chinese traditional medicine NiuBeiXiaoHe (NBXH) extracts have the function of antituberculosis and immune recovery in BALB/c Mice. J. Immunol. Res. 2021:6234560. doi: 10.1155/2021/6234560

LIONEX (2021). LIOFeron\$TB/LTBI IGRA [Online]. Germany: LIONEX. Available online at: https://lionex.de/product/lioferon/ (accessed May 17, 2021).

Litvinov, V. I., Shuster, A. M., Slogotskaia, L. V., Sel'tsovskii, P. P., Ovsiankina, E. S., Mushkin, A., et al. (2009). [Effectiveness of new diagnostic drug Diaskintest in children for tuberculosis diagnostic]. Probl. Tuberk. Bolezn. Legk. 2009, 19-22.

Liu, Y., Wang, J., and Wu, C. (2021). Microbiota and tuberculosis: a potential role of probiotics, and postbiotics. Front. Nutr. 8:626254. doi: 10.3389/fnut.2021. 626254

Louis, P. (1825). Recherches Anatomoco-Pathologiques sur la Phthisie. Paris: Chez Gabon et Compagnie.

Loxton, A. G., and van Rensburg, I. C. (2021). FasL regulatory B-cells during Mycobacterium tuberculosis infection and TB disease. J. Mol. Biol. 433:166984. doi: 10.1016/j.jmb.2021.166984

Luabeya, A. K., Kagina, B. M., Tameris, M. D., Geldenhuys, H., Hoff, S. T., Shi, Z., et al. (2015). First-in-human trial of the post-exposure tuberculosis vaccine H56:IC31 in Mycobacterium tuberculosis infected and non-infected healthy adults. Vaccine 33, 4130-4140. doi: 10.1016/j.vaccine.2015.06.051

Luo, J., Zhang, M., Yan, B., Li, F., Guan, S., Chang, K., et al. (2019). Diagnostic performance of plasma cytokine biosignature combination and MCP-1 as individual biomarkers for differentiating stages Mycobacterium tuberculosis infection. J. Infect. 78, 281-291. doi: 10.1016/j.jinf.2018.10.017

Luo, L., Zhu, L., Yue, J., Liu, J., Liu, G., Zhang, X., et al. (2017). Antigens Rv0310c and Rv1255c are promising novel biomarkers for the diagnosis of 
Mycobacterium tuberculosis infection. Emerg. Microbes Infect. 6:e64. doi: 10. 1038/emi.2017.54

Luo, W., Qu, Z. L., Xie, Y., Xiang, J., and Zhang, X. L. (2015). Identification of a novel immunodominant antigen Rv2645 from RD13 with potential as a cell-mediated immunity-based TB diagnostic agent. J. Infect. 71, 534-543. doi: 10.1016/j.jinf.2015.07.011

Lv, L., Li, C., Zhang, X., Ding, N., Cao, T., Jia, X., et al. (2017). RNA profiling analysis of the serum exosomes derived from patients with active and latent Mycobacterium tuberculosis infection. Front. Microbiol. 8:1051. doi: 10.3389/ fmicb.2017.01051

Mahmoudi, S., Pourakbari, B., and Mamishi, S. (2017). Interferon gamma release assay in response to PE35/PPE68 proteins: a promising diagnostic method for diagnosis of latent tuberculosis. Eur. Cytokine Netw. 28, 36-40. doi: 10.1684/ ecn. 2017.0391

Marino, S., Cilfone, N. A., Mattila, J. T., Linderman, J. J., Flynn, J. L., and Kirschner, D. E. (2015). Macrophage polarization drives granuloma outcome during Mycobacterium tuberculosis infection. Infect. Immun. 83, 324-338. doi: 10.1128/IAI.02494-14

Martineau, A. R., Newton, S. M., Wilkinson, K. A., Kampmann, B., Hall, B. M., Nawroly, N., et al. (2007). Neutrophil-mediated innate immune resistance to mycobacteria. J. Clin. Invest. 117, 1988-1994. doi: 10.1172/jci31097

Mateos, J., Estévez, O., González-Fernández, Á, Anibarro, L., Pallarés, Á, Reljic, R., et al. (2019). High-resolution quantitative proteomics applied to the study of the specific protein signature in the sputum and saliva of active tuberculosis patients and their infected and uninfected contacts. J. Proteomics 195, 41-52. doi: 10.1016/j.jprot.2019.01.010

Mayer-Barber, K. D., Andrade, B. B., Barber, D. L., Hieny, S., Feng, C. G., Caspar, P., et al. (2011). Innate and adaptive interferons suppress IL- $1 \alpha$ and IL$1 \beta$ production by distinct pulmonary myeloid subsets during Mycobacterium tuberculosis infection. Immunity 35, 1023-1034. doi: 10.1016/j.immuni.2011.12. 002

Mc, D. W. (1959). Inapparent infection: relation of latent and dormant infections to microbial persistence. Public Health Rep. 74, 485-499.

McCune, R. M. Jr., McDermott, W., and Tompsett, R. (1956). The fate of Mycobacterium tuberculosis in mouse tissues as determined by the microbial enumeration technique. II. The conversion of tuberculous infection to the latent state by the administration of pyrazinamide and a companion drug. J. Exp. Med. 104, 763-802. doi: 10.1084/jem.104.5.763

Meier, N. R., Jacobsen, M., Ottenhoff, T. H. M., and Ritz, N. (2018). A systematic review on Novel Mycobacterium tuberculosis antigens and their discriminatory potential for the diagnosis of latent and active tuberculosis. Front. Immunol. 9:2476. doi: 10.3389/fimmu.2018.02476

Mistry, R., Cliff, J. M., Clayton, C. L., Beyers, N., Mohamed, Y. S., Wilson, P. A., et al. (2007). Gene-expression patterns in whole blood identify subjects at risk for recurrent tuberculosis. J. Infect. Dis. 195, 357-365. doi: 10.1086/510397

Mori, G., Morrison, M., and Blumenthal, A. (2021). Microbiome-immune interactions in tuberculosis. PLoS Pathog. 17:e1009377. doi: 10.1371/journal. ppat.1009377

Mosavari, N., Karimi, A., Tadayon, K., Shahhosseini, G., Zavaran Hosseini, A., and Babaie, M. (2021). Evaluation of heating and irradiation methods for production of purified protein derivative (PPD) of Mycobacterium Tuberculosis. Arch. Razi. Inst. 75, 439-449. doi: 10.22092/ari.2019.123082.1238

Mukherjee, P., Dutta, M., Datta, P., Dasgupta, A., Pradhan, R., Pradhan, M., et al. (2007). The RD1-encoded antigen Rv3872 of Mycobacterium tuberculosis as a potential candidate for serodiagnosis of tuberculosis. Clin. Microbiol. Infect. 13, 146-152. doi: 10.1111/j.1469-0691.2006.01660.x

Mustafa, A. S., Cockle, P. J., Shaban, F., Hewinson, R. G., and Vordermeier, H. M. (2002). Immunogenicity of Mycobacterium tuberculosis RD1 region gene products in infected cattle. Clin. Exp. Immunol. 130, 37-42. doi: 10.1046/j.13652249.2002.01937.x

Ndzi, E. N., Nkenfou, C. N., Pefura, E. W. Y., Mekue, L. C. M., Guiedem, E., Nguefeu, C. N., et al. (2019). Tuberculosis diagnosis: algorithm that May discriminate latent from active tuberculosis. Heliyon 5:e02559. doi: 10.1016/j. heliyon.2019.e02559

Olivier, I., and Loots du, T. (2012). A metabolomics approach to characterise and identify various Mycobacterium species. J. Microbiol. Methods 88, 419-426. doi: 10.1016/j.mimet.2012.01.012
Pai, M., and Behr, M. (2016). Latent Mycobacterium tuberculosis infection and interferon-gamma release assays. Microbiol. Spectr. 4, 1-10. doi: 10.1128/ microbiolspec.TBTB2-0023-2016

Pan, L., Wei, N., Jia, H., Gao, M., Chen, X., Wei, R., et al. (2017). Genomewide transcriptional profiling identifies potential signatures in discriminating active tuberculosis from latent infection. Oncotarget 8, 112907-112916. doi: 10.18632/oncotarget.22889

Paquin-Proulx, D., Costa, P. R., Terrassani Silveira, C. G., Marmorato, M. P., Cerqueira, N. B., Sutton, M. S., et al. (2018). Latent Mycobacterium tuberculosis infection is associated with a higher frequency of mucosal-associated invariant $t$ and invariant natural killer T cells. Front. Immunol. 9:1394. doi: 10.3389/fimmu. 2018.01394

Pena, D., Rovetta, A. I., Hernandez Del Pino, R. E., Amiano, N. O., Pasquinelli, V., Pellegrini, J. M., et al. (2015). A Mycobacterium tuberculosis dormancy antigen differentiates latently infected bacillus calmette-guerin-vaccinated individuals. EBioMedicine 2, 884-890. doi: 10.1016/j.ebiom.2015.05.026

Petruccioli, E., Scriba, T. J., Petrone, L., Hatherill, M., Cirillo, D. M., Joosten, S. A., et al. (2016). Correlates of tuberculosis risk: predictive biomarkers for progression to active tuberculosis. Eur. Respir. J. 48, 1751-1763. doi: 10.1183/ 13993003.01012-2016

Phillips, M., Basa-Dalay, V., Bothamley, G., Cataneo, R. N., Lam, P. K., Natividad, M. P., et al. (2010). Breath biomarkers of active pulmonary tuberculosis. Tuberculosis (Edinb) 90, 145-151. doi: 10.1016/j.tube.2010.01.003

Phillips, M., Cataneo, R. N., Condos, R., Ring Erickson, G. A., Greenberg, J., La Bombardi, V., et al. (2007). Volatile biomarkers of pulmonary tuberculosis in the breath. Tuberculosis (Edinb) 87, 44-52. doi: 10.1016/j.tube.2006.03.004

Pourakbari, B., Mamishi, S., Benvari, S., and Mahmoudi, S. (2019). Comparison of the QuantiFERON-TB Gold Plus and QuantiFERON-TB Gold In-Tube interferon-gamma release assays: a systematic review and meta-analysis. $A d v$. Med. Sci. 64, 437-443. doi: 10.1016/j.advms.2019.09.001

Prabhavathi, M., Pathakumari, B., and Raja, A. (2015). IFN-gamma/TNF-alpha ratio in response to immuno proteomically identified human T-cell antigens of Mycobacterium tuberculosis - the most suitable surrogate biomarker for latent TB infection. J. Infect. 71, 238-249. doi: 10.1016/j.jinf.2015.04.032

Preez, I. D., Luies, L., and Loots, D. T. (2017). Metabolomics biomarkers for tuberculosis diagnostics: current status and future objectives. Biomark. Med. 11, 179-194. doi: 10.2217/bmm-2016-0287

Qiu, B., Liu, Q., Li, Z., Song, H., Xu, D., Ji, Y., et al. (2020). Evaluation of cytokines as a biomarker to distinguish active tuberculosis from latent tuberculosis infection: a diagnostic meta-analysis. BMJ Open 10:e039501. doi: 10.1136/ bmjopen-2020-039501

Rambaran, S., Naidoo, K., Lewis, L., Hassan-Moosa, R., Govender, D., Samsunder, N., et al. (2021). Effect of inflammatory cytokines/chemokines on pulmonary tuberculosis culture conversion and disease severity in HIV-Infected and uninfected individuals from South Africa. Front. Immunol. 12:641065. doi: 10.3389/fimmu.2021.641065

Ren, N., JinLi, J., Chen, Y., Zhou, X., Wang, J., Ge, P., et al. (2018). Identification of new diagnostic biomarkers for Mycobacterium tuberculosis and the potential application in the serodiagnosis of human tuberculosis. Microb. Biotechnol. 11, 893-904. doi: 10.1111/1751-7915.13291

Rodrigues, T. S., Conti, B. J., Fraga-Silva, T. F. C., Almeida, F., and Bonato, V. L. D. (2020). Interplay between alveolar epithelial and dendritic cells and Mycobacterium tuberculosis. J. Leukoc. Biol. 108, 1139-1156. doi: 10.1002/jlb. $4 \mathrm{mr} 0520-112 \mathrm{r}$

Rozot, V., Vigano, S., Mazza-Stalder, J., Idrizi, E., Day, C. L., Perreau, M., et al. (2013). Mycobacterium tuberculosis-specific CD8+ T cells are functionally and phenotypically different between latent infection and active disease. Eur. J. Immunol. 43, 1568-1577. doi: 10.1002/eji.201243262

Ruhwald, M., Aggerbeck, H., Gallardo, R. V., Hoff, S. T., Villate, J. I., Borregaard, B., et al. (2017). Safety and efficacy of the C-Tb skin test to diagnose Mycobacterium tuberculosis infection, compared with an interferon gamma release assay and the tuberculin skin test: a phase 3, double-blind, randomised, controlled trial. Lancet Respir. Med. 5, 259-268. doi: 10.1016/S2213-2600(16)30436-2

Ruhwald, M., Cayla, J., Aggerbaek, H., Dheda, K., and Andersen, P. L. (2016). Diagnostic accuracy of the novel C-Tb skin test for LTBI, results from two phase III trials. Eur. Respir. J. 48:OA3037. doi: 10.1183/13993003.congress2016.OA3037 
Ruibal, P., Voogd, L., Joosten, S. A., and Ottenhoff, T. H. M. (2021). The role of donor-unrestricted T-cells, innate lymphoid cells, and NK cells in antimycobacterial immunity. Immunol. Rev. 301, 30-47. doi: 10.1111/imr.12948

Saiboonjan, B., Roytrakul, S., Sangka, A., Lulitanond, V., Faksri, K., and Namwat, W. (2021). Proteomic analysis of drug-susceptible and multidrug-resistant nonreplicating Beijing strains of Mycobacterium tuberculosis cultured in vitro. Biochem. Biophys. Rep. 26:100960. doi: 10.1016/j.bbrep.2021.100960

Sakai, S., Kauffman, K. D., Oh, S., Nelson, C. E., Barry, C. E. III, and Barber, D. L. (2021). MAIT cell-directed therapy of Mycobacterium tuberculosis infection. Mucosal Immunol. 14, 199-208. doi: 10.1038/s41385-020-0332-4

Saracino, A., Scotto, G., Fornabaio, C., Martinelli, D., Faleo, G., Cibelli, D., et al. (2009). QuantiFERON-TB Gold In-Tube test (QFT-GIT) for the screening of latent tuberculosis in recent immigrants to Italy. New Microbiol. 32, 369-376.

Schoeman, J. C., du Preez, I., and Loots du, T. (2012). A comparison of four sputum pre-extraction preparation methods for identifying and characterising Mycobacterium tuberculosis using GCxGC-TOFMS metabolomics. J. Microbiol. Methods 91, 301-311. doi: 10.1016/j.mimet.2012.09.002

Scordo, J. M., Knoell, D. L., and Torrelles, J. B. (2016). Alveolar epithelial cells in Mycobacterium tuberculosis infection: active players or innocent bystanders? J. Innate Immun. 8, 3-14. doi: 10.1159/000439275

Shin, J. H., Yang, J. Y., Jeon, B. Y., Yoon, Y. J., Cho, S. N., Kang, Y. H., et al. (2011). (1)H NMR-based metabolomic profiling in mice infected with Mycobacterium tuberculosis. J. Proteome Res. 10, 2238-2247. doi: 10.1021/pr101054m

Somashekar, B. S., Amin, A. G., Tripathi, P., MacKinnon, N., Rithner, C. D., Shanley, C. A., et al. (2012). Metabolomic signatures in guinea pigs infected with epidemic-associated W-Beijing strains of Mycobacterium tuberculosis. J. Proteome Res. 11, 4873-4884. doi: 10.1021/pr300345x

Sotgiu, G., Saderi, L., Petruccioli, E., Aliberti, S., Piana, A., Petrone, L., et al. (2019). QuantiFERON TB Gold Plus for the diagnosis of tuberculosis: a systematic review and meta-analysis. J. Infect. 79, 444-453. doi: 10.1016/j.jinf.2019.08.018

Starshinova, A., Dovgalyk, I., Malkova, A., Zinchenko, Y., Pavlova, M., Belyaeva, E., et al. (2020). Recombinant tuberculosis allergen (Diaskintest $((\mathrm{R}))$ ) in tuberculosis diagnostic in Russia (meta-analysis). Int. J. Mycobacteriol. 9, 335346. doi: 10.4103/ijmy.ijmy_131_20

Steffen, R. E., Pinto, M., Kritski, A., and Trajman, A. (2020). Cost-effectiveness of newer technologies for the diagnosis of Mycobacterium tuberculosis infection in Brazilian people living with HIV. Sci. Rep. 10:21823. doi: 10.1038/s41598-02078737-w

Stop TB Partnership (2015). The Global Plan to End TB. Geneva: Stop TB Partnership.

Sudbury, E. L., Clifford, V., Messina, N. L., Song, R., and Curtis, N. (2020). Mycobacterium tuberculosis-specific cytokine biomarkers to differentiate active TB and LTBI: a systematic review. J. Infect. 81, 873-881. doi: 10.1016/j.jinf.2020. 09.032

Sun, H., Pan, L., Jia, H., Zhang, Z., Gao, M., Huang, M., et al. (2018). Label-free quantitative proteomics identifies novel plasma biomarkers for distinguishing pulmonary tuberculosis and latent infection. Front. Microbiol. 9:1267. doi: 10. 3389/fmicb.2018.01267

Syhre, M., and Chambers, S. T. (2008). The scent of Mycobacterium tuberculosis. Tuberculosis (Edinb) 88, 317-323. doi: 10.1016/j.tube.2008.01.002

Syhre, M., Manning, L., Phuanukoonnon, S., Harino, P., and Chambers, S. T. (2009). The scent of Mycobacterium tuberculosis-part II breath. Tuberculosis (Edinb) 89, 263-266. doi: 10.1016/j.tube.2009.04.003

Tailleux, L., Schwartz, O., Herrmann, J. L., Pivert, E., Jackson, M., Amara, A., et al. (2003). DC-SIGN is the major Mycobacterium tuberculosis receptor on human dendritic cells. J. Exp. Med. 197, 121-127. doi: 10.1084/jem.20021468

Theel, E. S., Hilgart, H., Breen-Lyles, M., McCoy, K., Flury, R., Breeher, L. E., et al. (2018). Comparison of the QuantiFERON-TB Gold Plus and QuantiFERONTB Gold In-Tube Interferon Gamma Release Assays in Patients at Risk for Tuberculosis and in Health Care Workers. J. Clin. Microbiol. 56, e00614-18. doi: 10.1128/JCM.00614-18

Tolosie, K., and Sharma, M. K. (2014). Application of cox proportional hazards model in case of tuberculosis patients in selected addis ababa health centres, ethiopia. Tuberc. Res. Treat. 2014:536976. doi: 10.1155/2014/536976

Venkatappa, T. K., Punnoose, R., Katz, D. J., Higgins, M. P., Banaei, N., Graviss, E. A., et al. (2019). Comparing QuantiFERON-TB gold plus with other tests to diagnose Mycobacterium tuberculosis infection. J. Clin. Microbiol. 57, e0098519. doi: $10.1128 / J C M .00985-19$
Villate, J. I., Ibáñez, B., Cabriada, V., Pijoán, J. I., Taboada, J., and Urkaregi, A. (2006). Analysis of latent tuberculosis and mycobacterium avium infection data using mixture models. BMC Public Health 6:240. doi: 10.1186/1471-2458-6240

Vinuesa, C. G., Toellner, K. M., and Papa, I. (2016). "Extrafollicular antibody responses," in Encyclopedia of Immunobiology, ed. M. J. H. Ratcliffe (Oxford: Academic Press), 208-215.

Wang, J., Qie, Y., Zhang, H., Zhu, B., Xu, Y., Liu, W., et al. (2008). PPE protein (Rv3425) from DNA segment RD11 of Mycobacterium tuberculosis: a novel immunodominant antigen of Mycobacterium tuberculosis induces humoral and cellular immune responses in mice. Microbiol. Immunol. 52, 224-230. doi: 10.1111/j.1348-0421.2008.00029.x

Wang, S., Chen, J., Zhang, Y., Diao, N., Zhang, S., Wu, J., et al. (2013). Mycobacterium tuberculosis region of difference (RD) 2 antigen Rv1985c and RD11 antigen Rv3425 have the promising potential to distinguish patients with active tuberculosis from M. bovis BCG-vaccinated individuals. Clin. Vaccine Immunol. 20, 69-76. doi: 10.1128/cvi.00481-12

Wang, S., Li, Y., Shen, Y., Wu, J., Gao, Y., Zhang, S., et al. (2018). Screening and identification of a six-cytokine biosignature for detecting TB infection and discriminating active from latent TB. J. Transl. Med. 16:206. doi: 10.1186/ s12967-018-1572-X

Watson, A., Li, H., Ma, B., Weiss, R., Bendayan, D., Abramovitz, L., et al. (2021). Human antibodies targeting a Mycobacterium transporter protein mediate protection against tuberculosis. Nat. Commun. 12:602. doi: 10.1038/s41467021-20930-0

Weiner, J. III, Parida, S. K., Maertzdorf, J., Black, G. F., Repsilber, D., Telaar, A., et al. (2012). Biomarkers of inflammation, immunosuppression and stress with active disease are revealed by metabolomic profiling of tuberculosis patients. PLoS One 7:e40221. doi: 10.1371/journal.pone.0040221

Westphalen, K., Gusarova, G. A., Islam, M. N., Subramanian, M., Cohen, T. S., Prince, A. S., et al. (2014). Sessile alveolar macrophages communicate with alveolar epithelium to modulate immunity. Nature 506, 503-506. doi: 10.1038/ nature 12902

WHO (2015). WHO Guidelines Approved by the Guidelines Review Committee," in Guidelines on the Management of Latent Tuberculosis Infection. Geneva: World Health Organization, 33.

WHO (2018). Global Tuberculosis Report 2018. Geneva: World Health Organization.

WHO (2020). Global Tuberculosis Report 2020. Geneva: World Health Organization.

Wipperman, M. F., Bhattarai, S. K., Vorkas, C. K., Maringati, V. S., Taur, Y., Mathurin, L., et al. (2021). Gastrointestinal microbiota composition predicts peripheral inflammatory state during treatment of human tuberculosis. Nat. Commun. 12:1141. doi: 10.1038/s41467-021-21475-y

Won, E. J., Choi, J. H., Cho, Y. N., Jin, H. M., Kee, H. J., Park, Y. W., et al. (2017). Biomarkers for discrimination between latent tuberculosis infection and active tuberculosis disease. J. Infect. 74, 281-293. doi: 10.1016/j.jinf.2016.11.010

Wu, J., Bai, J., Wang, W., Xi, L., Zhang, P., Lan, J., et al. (2019). ATBdiscrimination: an in silico tool for identification of active tuberculosis disease based on routine blood test and T-SPOT.TB detection results. J. Chem. Inf. Model. 59, 4561-4568. doi: 10.1021/acs.jcim.9b00678

Yan, Z. H., Yi, L., Wei, P. J., Jia, H. Y., Wang, J., Wang, X. J., et al. (2018). Evaluation of panels of Mycobacterium tuberculosis antigens for serodiagnosis of tuberculosis. Int. J. Tuberc. Lung Dis. 22, 959-965. doi: 10.5588/ijtld.18. 0060

Yang, C. T., Cambier, C. J., Davis, J. M., Hall, C. J., Crosier, P. S., and Ramakrishnan, L. (2012). Neutrophils exert protection in the early tuberculous granuloma by oxidative killing of mycobacteria phagocytosed from infected macrophages. Cell Host Microbe 12, 301-312. doi: 10.1016/j.chom.2012.07.009

Yang, D. (2018). Epitope Prediction, Recombinant Protein Preparation and Immunological Characteristics Of Mycobacterium Tuberculosis rv2657c. Master. Zhangjiakou: Hebei North University.

Yang, X., Zhang, J., Liang, Q., Pan, L., Duan, H., Yang, Y., et al. (2021). Use of T-SPOT.TB for the diagnosis of unconventional pleural tuberculosis is superior to ADA in high prevalence areas: a prospective analysis of 601 cases. BMC Infect. Dis. 21:4. doi: 10.1186/s12879-020-05676-2

Zellweger, J. P., Sotgiu, G., Corradi, M., and Durando, P. (2020). The diagnosis of latent tuberculosis infection (LTBI): currently available tests, future 
developments, and perspectives to eliminate tuberculosis (TB). Med. Lav. 111, 170-183. doi: 10.23749/mdl.v111i3.9983

Zhang, H., Wang, J., Lei, J., Zhang, M., Yang, Y., Chen, Y., et al. (2007). PPE protein (Rv3425) from DNA segment RD11 of Mycobacterium tuberculosis: a potential B-cell antigen used for serological diagnosis to distinguish vaccinated controls from tuberculosis patients. Clin. Microbiol. Infect. 13, 139-145. doi: $10.1111 / j .1469-0691.2006 .01561 . x$

Zhou, A., Ni, J., Xu, Z., Wang, Y., Lu, S., Sha, W., et al. (2013). Application of (1)h NMR spectroscopy-based metabolomics to sera of tuberculosis patients. J. Proteome Res. 12, 4642-4649. doi: 10.1021/pr40k 07359

Zhou, Y., Du, J., Hou, H. Y., Lu, Y. F., Yu, J., Mao, L. Y., et al. (2017). Application of immunoscore model for the differentiation between active tuberculosis and latent tuberculosis infection as well as monitoring antituberculosis therapy. Front. Cell Infect. Microbiol. 7:457. doi: 10.3389/fcimb.201 7.00457
Conflict of Interest: The authors declare that the research was conducted in the absence of any commercial or financial relationships that could be construed as a potential conflict of interest.

Publisher's Note: All claims expressed in this article are solely those of the authors and do not necessarily represent those of their affiliated organizations, or those of the publisher, the editors and the reviewers. Any product that may be evaluated in this article, or claim that may be made by its manufacturer, is not guaranteed or endorsed by the publisher.

Copyright $\odot 2021$ Gong and Wu. This is an open-access article distributed under the terms of the Creative Commons Attribution License (CC BY). The use, distribution or reproduction in other forums is permitted, provided the original author(s) and the copyright owner(s) are credited and that the original publication in this journal is cited, in accordance with accepted academic practice. No use, distribution or reproduction is permitted which does not comply with these terms. 